\title{
REVIEW ARTICLE Chitinase-3 like-protein-1 function and its role in diseases
}

\author{
Ting Zhao', Zhongping $\mathrm{Su}^{2}$, Yingchang $\mathrm{Li}^{1,3}$, Xiaoren Zhang ${ }^{1,3}$ and Qiang You $\mathbb{C}^{1,2,3}$
}

Non-enzymatic chitinase-3 like-protein-1 (CHI3L1) belongs to glycoside hydrolase family 18 . It binds to chitin, heparin, and hyaluronic acid, and is regulated by extracellular matrix changes, cytokines, growth factors, drugs, and stress. CHI3L1 is synthesized and secreted by a multitude of cells including macrophages, neutrophils, synoviocytes, chondrocytes, fibroblast-like cells, smooth muscle cells, and tumor cells. It plays a major role in tissue injury, inflammation, tissue repair, and remodeling responses. CHI3L1 has been strongly associated with diseases including asthma, arthritis, sepsis, diabetes, liver fibrosis, and coronary artery disease. Moreover, following its initial identification in the culture supernatant of the MG63 osteosarcoma cell line, CHI3L1 has been shown to be overexpressed in a wealth of both human cancers and animal tumor models. To date, interleukin-13 receptor subunit alpha-2, transmembrane protein 219, galectin-3, chemo-attractant receptor-homologous 2, and CD44 have been identified as CHI3L1 receptors. CHI3L1 signaling plays a critical role in cancer cell growth, proliferation, invasion, metastasis, angiogenesis, activation of tumor-associated macrophages, and Th2 polarization of CD4 ${ }^{+}$T cells. Interestingly, CHI3L1-based targeted therapy has been increasingly applied to the treatment of tumors including glioma and colon cancer as well as rheumatoid arthritis. This review summarizes the potential roles and mechanisms of $\mathrm{CHI} 3 \mathrm{~L} 1$ in oncogenesis and disease pathogenesis, then posits investigational strategies for targeted therapies.

Signal Transduction and Targeted Therapy (2020)5:201

; https://doi.org/10.1038/s41392-020-00303-7

\section{INTRODUCTION}

Glycoside hydrolase family 18 includes chitinases and nonenzymatic chitinase-like proteins (CLPs), both of which bind chitin, a polysaccharide chain composed of $\mathrm{N}$-acetylglucosamine repeats and present in arthropods and other taxa as a major structural polymer. While chitinases cleave chitin, CLPs do not possess this enzymatic activity. chitinase-3 like-protein-1 (CHI3L1), one of the CLPs, also has been named YKL-40 in humans and breast regression protein 39 (BRP-39) in mice, is common in both prokaryotes and eukaryotes. Following its initial discovery in the culture supernatant of the osteosarcoma cell line MG63, ${ }^{1}$ it was subsequently detected in human chondrocytes, synoviocytes, and vascular smooth muscle cells. ${ }^{2,3}$ In fact, CHI3L1 is produced by a multitude of cells, including macrophages, neutrophils, fibroblastlike cells, hepatic stellate cells, endothelial cells, and cancer cells. ${ }^{4-9}$ For the moment, extracellular matrix (ECM) changes, miRNAs, growth factors, cytokines, stress, and drugs have been reported to be effective regulators of the synthesis and secretion of CHI3L1. ${ }^{10-13}$

The crystal structure of the native protein shows that $\mathrm{CHI}$ L 1 consists of a $(\beta / a)_{8}$-barrel fold with a $\beta+a$ domain insertion, ${ }^{14,15}$ which are essential for its functions in both physiological and pathological processes. CHI3L1 plays a crucial role in protecting against pathogens, antigen-induced and oxidant-induced injury responses, inflammation, and tissue repair and remodeling by regulating a variety of essential biological processes including oxidant injury, apoptosis, pyroptosis, inflammasome activation, Th1/Th2 inflammatory balance, M2 macrophage differentiation, dendritic cell (DC) accumulation, TGF- $\beta 1$ expression, ECM regulation, and parenchymal scarring. ${ }^{16-19}$

CHI3L1 is overexpressed in many human cancer types and animal tumor models, for instance, oligodendroglia, glioblastoma, osteosarcoma, sarcoma, colon, and gastric cancers (GCs)..$^{20-27}$ Elevated serum levels of CHI3L1 have been found to be associated with poor prognosis and shorter survival in patients with metastatic cancer. ${ }^{28}$ Consequently, CHI3L1 has been increasingly proposed as a sensitive biomarker and an attractive therapeutic target for several certain types of cancers. ${ }^{29}$ Interleukin-13 receptor subunit alpha-2 (IL-13Ra2), and its interactions with transmembrane protein 219 (TMEM219), galectin-3 (Gal-3), and CD44 have been identified to be receptors of CHI3L1 respectively. ${ }^{30-32}$ Additionally, collaboration of integrin $a_{v} \beta_{3}$ with syndecan-1 (Syn-1), and coordination between integrin $\alpha_{v} \beta_{5}$ and Syn-1 are newly discovered interactions that are activated by $\mathrm{CHI} 3 \mathrm{~L} 1$ to trigger signaling pathways and downstream cascades. ${ }^{33,34}$ However, the underlying mechanisms involved are unclear, with key downstream targets remaining to be deeply identified.

In this review, we discuss the sources, regulation, crystal structure, biological functions, and the potential roles of $\mathrm{CHI}$ L1 in oncogenesis and disease pathogenesis. Accordingly, we have also illustrated various applied targeting therapies and proposed certain theoretically feasible strategies.

\footnotetext{
${ }^{1}$ Affiliated Cancer Hospital \& Institute, Guangzhou Medical University, Guangzhou, China; ${ }^{2}$ Department of Biotherapy, Department of Geriatrics, Second Affiliated Hospital of Nanjing Medical University, Nanjing, China and ${ }^{3}$ Key Laboratory of Cell Homeostasis and Cancer Research of Guangdong Higher Education Institutes, Guangzhou Medical University, Guangzhou, China

Correspondence: Qiang You (qiang.you@live.com)

These authors contributed equally: Ting Zhao, Zhongping Su.
}

Received: 23 April 2020 Revised: 28 July 2020 Accepted: 20 August 2020

Published online: 14 September 2020 


\section{GENETIC VARIANTS AND CRYSTAL STRUCTURE OF CHI3L1}

The human $\mathrm{CHI} 3 \mathrm{~L} 1$ gene is located on chromosome 1q31-1q32, comprising 7498 base pairs and 10 exons. It spans $\sim 8 \mathrm{kbp}$ of genomic DNA. ${ }^{35}$ Three promoter single-nucleotide polymorphisms (SNPs) (rs4950928, rs10399805, and rs10399931), 1 nonsynonymous SNP (rs880633), and four intronic SNPs (rs1538372, rs2071579, rs946259, and rs2275353) in CHI3L1 have been found to be linked with its serum level in the general population, at or below genome-wide association significance levels. ${ }^{36}$ Accordingly, genetic variation in CHI3L1 is closely associated with the incidence and prognosis of multiple inflammatory and neoplastic diseases. ${ }^{37,38}$ In asthma patients with European ancestry, the risk allele $A$ at rs12141494 has been found to be associated with higher levels of CHI3L1 in the airway and severe asthma. ${ }^{39}$ Similarly, in the southwest Chinese Han population, the rs10399931 CT/TT genotypes of CHI3L1 were associated with increased risk of asthma. ${ }^{40}$

CHI3L1 is an indispensable member of the glycoside hydrolase family $18,{ }^{41}$ which binds to chitin, but lacks enzymatic activity. ${ }^{41,42}$ Crystal diffraction studies revealed that the three-dimensional structure of $\mathrm{CHI} 3 \mathrm{~L} 1$ consisted of an $(\beta / a)_{8}$-barrel domain with a second domain composed of six antiparallel $\beta$-strands, with one $\alpha-$ helix $(a+\beta)$ domain inserted after strand $\beta 7$ (Fig. 1a: https://doi. org/10.2210/pdb1NWU/pdb). ${ }^{14,15}$ Additionally, a 43-residue carbohydrate-binding cleft was found exposed at the C-terminal side of the $\beta$-strands in the $(\beta / \alpha)_{8}$ barrel. ${ }^{43}$ Essentially, the protein-carbohydrate interactions are dominated by stacking of the sides. ${ }^{43}$ This structure suggests that CHI3L1 acts as a sensor to turn on innate defenses and regulates inflammatory responses as a consequence of infection, which can also contribute to tumorigenesis.

\section{SOURCE AND EXPRESSION OF CHI3L1}

CHI3L1 was originally discovered in the culture supernatant of MG63 cell lines. 'It was also identified in the monolayer or explant culture of human articular chondrocytes, and was termed human cartilage glycoprotein-39 (HC-gp39). ${ }^{2}$ It has been named YKL-40, owing to the three $\mathrm{N}$-terminal amino-acid residues present in the secreted form: tyrosine $(\mathrm{Y})$, lysine $(\mathrm{K})$, and leucine $(\mathrm{L})$ with a molecular weight of $40 \mathrm{kDa} .{ }^{44}$

CHI3L1 is produced by a multitude of cells including macrophages, neutrophils, stem cells, bone cells, synoviocytes, chondrocytes, fibroblast-like cells, endothelial cells, vascular smooth muscle cells, hepatic stellate cells, mammary epithelial cells, and cancer cells. ${ }^{42,45-48}$ Overexpression of CHI3L1 has been observed in a number of inflammatory conditions including asthma, sepsis, diabetes, cirrhosis, preeclampsia, rheumatoid arthritis, and coronary artery disease. $33,38,49-54$

\section{REGULATION OF CHI3L1 EXPRESSION}

At the gene level, miR-24 shows strong complementarity and a high degree of species conservation with respect to its binding sites within the $3^{\prime}$ UTR of the CHI3L1 mRNA. ${ }^{55}$ Consequently, miR24 was found to downregulate the expression of CHI3L1 in S. aureus-infected MC3T3-E1 cells ${ }^{56}$ and block the induction of CHI3L1, which attenuates aortic vascular inflammation and the development of murine abdominal aneurysms. ${ }^{57}$ Similarly, following hepatitis $\mathrm{C}$ virus (HCV) infection miRNA-449a was found to modulate the expression of $\mathrm{CHI} 3 \mathrm{~L} 1$ by targeting the components of the NOTCH signaling pathway. ${ }^{58}$ Recent studies have revealed that miR-342-3p suppresses NF-kB-mediated CHI3L1 expression during vascular inflammation and atherosclerosis to prevent memory dysfunction. ${ }^{59}$

At the cellular level, cytokines, growth factors, cellular and ECM factors, drugs, and stress are effective regulators of CHI3L1 production. For example, changes in the ECM of chondrocytes has been linked to the synthesis and secretion of CHI3L1 [54]. IL-1 $\beta$ and TGF- $\beta$ have been reported to inhibit the expression of $C H I 3 L 1$ mRNA in human chondrocytes and cartilage explant cultures. ${ }^{11}$ Conversely, IL-1 $\beta$ facilitates the production of CHI3L1 in SW480 and T84 cell lines. A similar effect has been reported to be caused by TNFa, Th1 (IFN- $\gamma$ ), and Th2 (IL-4 and IL-13). ${ }^{60} \mathrm{CHI} 3 \mathrm{~L} 1$ production has also been reported to be enhanced by the key Th1 cytokine, IFN- $\gamma$, and suppressed by the Th2 cytokine, IL-4, in activated macrophages. ${ }^{13}$ Stimulation by IL-6, IL-17, and IL-18 has resulted in CHI3L1 secretion from freshly isolated chondrocytes. ${ }^{5,6,61}$ However, IL-7, IL-11, IL-12, PDGF, and bFGF have no such effect on CHI3L1 synthesis and secretion in human chondrocyte and cartilage explant cultures. ${ }^{11}$ IGF-I and IGF-II stimulate CHI3L1 synthesis in guinea pig chondrocytes, but have no effect on human chondrocytes. ${ }^{2,12}$ CHI3L1 is overexpressed in U87 MG cells cultured under stresses including hypoxia, ionizing radiation, confluence, etoposide ceramide, p53 inhibition, antioxidant treatment, and serum depletion. Conversely, TNFa and bFGF exert an inhibitory influence on CHI3L1 production $^{6}$ (Table 1, Fig. 1b).

\section{BIOLOGICAL ACTIVITIES OF CHI3L1}

\section{CHI3L1 stimulates cell growth and proliferation}

CHI3L1 promotes the growth and proliferation of guinea pig chondrocytes, rabbit chondrocytes, and synovial cells. ${ }^{61}$ In humans, CHI3L1 facilitates the growth of synovial cells, articular chondrocytes, skin, and fetal lung fibroblasts through the phosphorylation of MAPK and Akt signaling. ${ }^{5}$ Accordingly, CHI3L1 silencing decreases the proliferation of HEK293 and U87 cells. ${ }^{41,62,63}$ During asthma, CHI3L1 increases bronchial smooth-muscle cell growth and proliferation through PAR-2dependent, Akt-dependent, Erk-dependent, and p38-dependent mechanisms. ${ }^{33}$ In the tissue repair and remodeling of asthma, CHI3L1 was found to induce IL-8 expression in bronchial epithelium, via MAPK (JNK and Erk) and NF-KB pathways, to stimulate bronchial smooth muscle cell proliferation. ${ }^{64}$ CHI3L1 also works synergistically with IGF-1 to stimulate the growth of fibroblasts by initiating MAPK/Erk $1 / 2$ and phosphatidylinositol 3 kinase (PI3K) signaling cascades that play a major role in tissue fibrosis. ${ }^{5}$ Essentially, both MAPK and PI3K pathways are important in mitogenesis, growth, proliferation, apoptosis, and cancer-cell transformation. ${ }^{65}$

CHI3L1 has a chemotactic effect on vascular endothelium and smooth-muscle cells during tissue injury and remodeling, inflammation, and fibrosis. ${ }^{6}$ It regulates the morphology of vascular endothelial cells by stimulating endothelium tubulogenesis and vascular smooth muscle cell migration and adhesion. ${ }^{66}$

\section{CHI3L1 promotes cell survival}

CHI3L1 has been found to protect cardiomyocytes from apoptosis during ischemia-reperfusion injury. ${ }^{67}$ It also has a pro-inflammatory function in reducing inflammatory cell apoptosis and death, by inhibiting Fas expression through the phosphorylation of protein kinase B (PKB)/Akt. ${ }^{68}$ Similarly, CHI3L1 has been reported as a potent inhibitor of death receptor-induced inflammatory cell apoptosis, which is accomplished through Fas expression inhibition, PKB/Akt activation, and Faim 3 induction. ${ }^{69}$ One group has reported that phosphorylation of PKB/Akt correlates closely with cell apoptosis and survival. ${ }^{70}$

CHI3L1 inhibition by shRNA increases cell death triggered by several anticancer drugs, including cisplatin, etoposide, and doxorubicin, whereas overexpressed $\mathrm{CHI} 3 \mathrm{~L} 1$ exhibits the opposite effect in glioblastoma U87 MG cells. ${ }^{41}$ Particularly in late-stage glioblastoma, $\mathrm{CHI} \mathrm{L} 11$ regulates tumorigenesis by interrupting the pathways leading to apoptosis. ${ }^{6}$ Additionally, CHI3L1 also protects cancer cells from apoptosis by remodeling the ECM to create a good substrate for tumor growth and progress. ${ }^{71}$ 
a
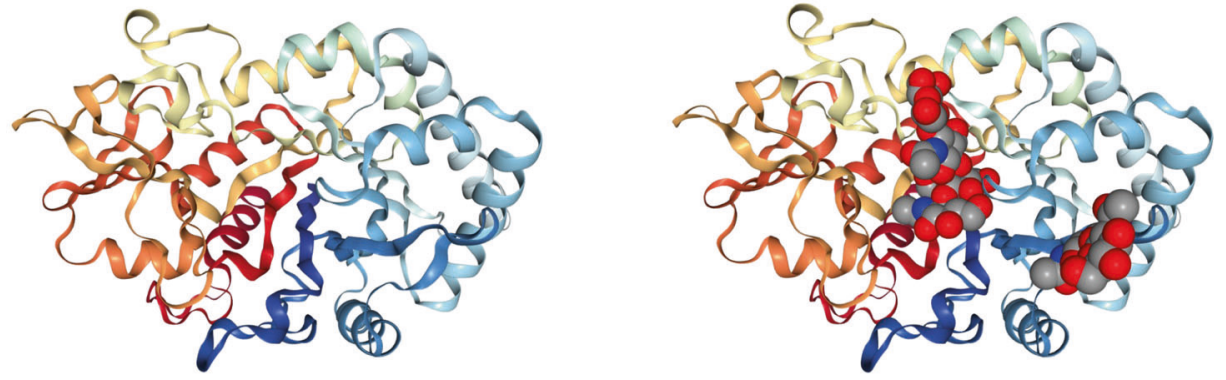

b

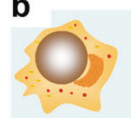

Macrophage

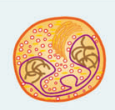

Neutrophil

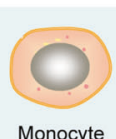

Monocyte

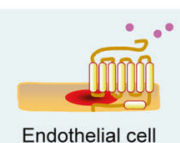

Endothelial cell

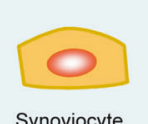

Synoviocyte

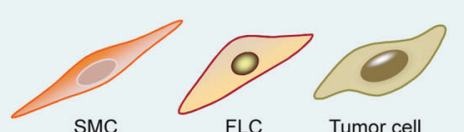

SMC
FLC

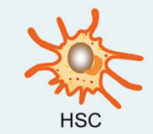

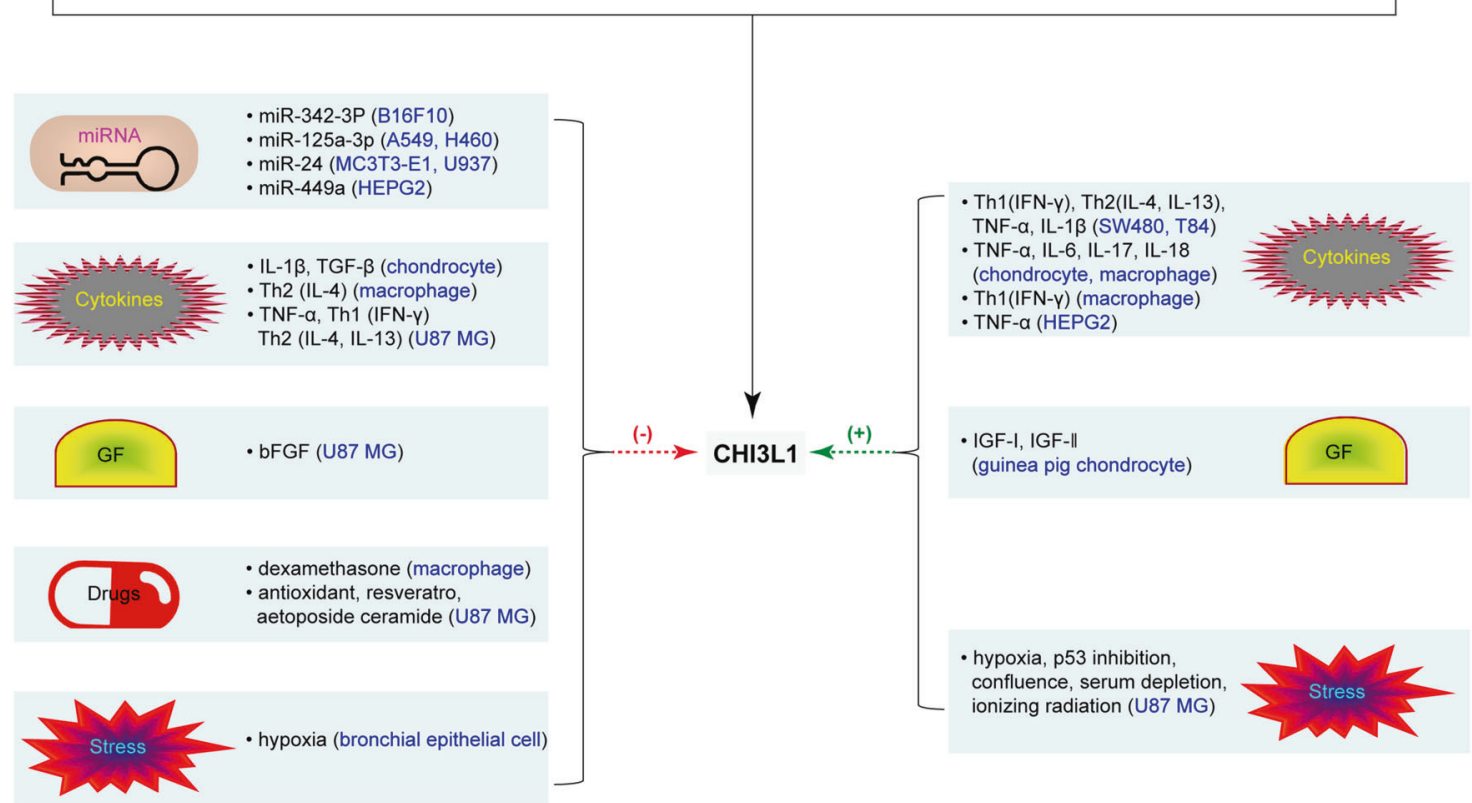

Fig. 1 Crystal structure, source, and expression regulation of CHI3L1. a A long carbohydrate-binding cleft is present at the C-terminal side of the beta-strands. Binding of chitotetraose is shown in the groove. b CHI3L1 is synthesized and secreted by a multitude of cells. CHI3L1 expression is regulated by miRNAs, cytokines, growth factors (GF), drugs, and stress. SMC smooth muscle cell, FLC fibroblast like cells, HSC hepatic stellate cell

CHI3L1 drives immune cell activation and differentiation

CHI3L1 has a significant impact on macrophage differentiation, DC accumulation, and Th1/Th2 balance. $^{18}$ In contrast to other monocyte/macrophage markers, CHI3L1 is not found in monocytes, but is strongly induced during the late stages of differentiation in human macrophages, where nuclear Sp1 binds to the CHI3L1 promoter to facilitate the late stages of human macrophage maturation. ${ }^{72}$

CHI3L1 plays a significant role in the pathogenesis of CD4 $\mathrm{T}^{+}$ cell polarization and Th2 inflammation. CHI3L1-deficient CD4 ${ }^{+}$ $\mathrm{T}$ cells differentiate into Th1 cells. $^{73}$ Essentially, CHI3L1 is expressed in activated T cells and Th2 cells, regulating Th1 and Th2 differentiation through IFN- $\gamma$ signaling via the IFN $-\gamma-S T A T 1$ axis. $^{73}$ Therefore, CHI3L1 is a regulator of Th1 polarization and cytotoxic T lymphocyte (CTL) expression, which serve as potential therapeutic targets to enhance anti-tumor immunity. CHI3L1 expression is greatly enhanced during Th2 inflammatory responses induced by ovalbumin, aluminum hydroxide, house dust, and mites, while CHI3L1 knockout mice exhibit reduced Th2 inflammation. ${ }^{69}$ CHI3L1 expression is induced by a high-fat diet and contributes to the genesis of obesity and asthma by the inhibition of sirt1 expression. ${ }^{74} \mathrm{CHI}$ L1 1 is expressed in a timedependent manner during the differentiation and maturation of monocyte-derived DCs, and distributed in the cytoplasm and nucleus of both immature and mature DCs. ${ }^{75}$

$\mathrm{CHI} 3 \mathrm{~L} 1$ regulates the synthesis and degradation of the ECM The ECM, a collection of extracellular molecules, provides structural and biochemical support to surrounding cells, ${ }^{76}$ also participating in gene expression, cellular differentiation, cell adhesion, and intercellular communication. ${ }^{77,78}$ Increased ECM degradation promotes cell migration, invasion, and tumorigenesis. The ECM barrier represents the first obstacle for invasive tumor migration and establishment of metastases. ${ }^{79}$ It has been shown that CHI3L1 inhibits the degradation of type I collagen and hyaluronic acid. It also affects the enzymatic activity of matrix metalloproteinases (MMPs), thereby influencing the extent of cell adhesion and migration, ${ }^{80}$ influencing tissue remodeling, fibrosis, and tumorigenesis. CHI3L1 suppresses the expression of Ecadherin while enhancing the activity of MMP-9 and cell motility, to mediate mammary tissue remodeling during involution. ${ }^{81}$ Essentially, the absence of E-cadherin function, which leads to 
Table 1. Regulation of $\mathrm{CHI} 3 \mathrm{~L} 1$ expression

\begin{tabular}{|c|c|c|c|c|}
\hline Types & & Targeted cell & & References \\
\hline \multirow[t]{4}{*}{ Gene level } & miR-342-3p & B16F10 cell lines & $\downarrow$ & 263 \\
\hline & $\operatorname{miR}-125 a-3 p$ & $\begin{array}{l}\text { A549, H460 } \\
\text { cell lines }\end{array}$ & $\downarrow$ & 264 \\
\hline & miR-24 & $\begin{array}{l}\text { MC3T3-E1 cell, } \\
\text { U937 cell }\end{array}$ & $\downarrow$ & $55,56,149$ \\
\hline & miR-449a & HEPG2 cells & $\downarrow$ & 58 \\
\hline Cellular level & ECM & & $\uparrow$ & 265 \\
\hline \multirow[t]{8}{*}{ Cytokines } & $\begin{array}{l}\text { Th1 (IFN- } \gamma \text { ), Th2 (IL- } \\
\text { 4, IL-13), } \\
\text { TNF } \alpha, \text { IL-1 } \beta\end{array}$ & $\begin{array}{l}\text { SW480 and T84 } \\
\text { cell lines }\end{array}$ & $\uparrow$ & $29,60,118$ \\
\hline & $\begin{array}{l}\text { IL-6, IL-17, IL-18, } \\
\text { TNF } \alpha\end{array}$ & $\begin{array}{l}\text { Chondrocytes, } \\
\text { macrophages }\end{array}$ & $\uparrow$ & $266-268$ \\
\hline & IL-1 $\beta$, TGF- $\beta$ & Chondrocytes & $\downarrow$ & 11 \\
\hline & Th1 $($ IFN- $\gamma)$ & Macrophages & $\uparrow$ & 13 \\
\hline & Th2 (IL-4) & Macrophages & $\downarrow$ & 13 \\
\hline & TNF $\alpha$ & HEPG2 cells, & $\uparrow$ & 58 \\
\hline & & $\begin{array}{l}\text { Human skeletal } \\
\text { muscle cells }\end{array}$ & $\uparrow$ & 9 \\
\hline & $\begin{array}{l}\text { TNF } \alpha, \text { Th1 (IFN- } \gamma) \text {, } \\
\text { Th2 (IL-4, IL-13) }\end{array}$ & U87 MG cell lines & $\downarrow$ & 6 \\
\hline \multirow[t]{2}{*}{ Growth factors } & IGF-I, IGF-II & $\begin{array}{l}\text { Guinea pig } \\
\text { chondrocytes }\end{array}$ & $\uparrow$ & 2,12 \\
\hline & bFGF & U87 MG cell lines & $\downarrow$ & 6 \\
\hline \multirow[t]{3}{*}{ Drugs } & Dexamethasone, & Macrophages & $\downarrow$ & 13 \\
\hline & $\begin{array}{l}\text { Etoposide } \\
\text { ceramide, }\end{array}$ & U87 MG cell lines & $\downarrow$ & 6,258 \\
\hline & $\begin{array}{l}\text { Antioxidant, } \\
\text { resveratrol }\end{array}$ & & & \\
\hline \multirow[t]{2}{*}{ Stress } & $\begin{array}{l}\text { Hypoxia, } \\
\text { confluence, p53 } \\
\text { inhibition, } \\
\text { serum depletion, } \\
\text { lonizing radiation }\end{array}$ & U87 MG cell lines & $\uparrow$ & 6 \\
\hline & Hypoxia & $\begin{array}{l}\text { Bronchial } \\
\text { epithelial cells }\end{array}$ & $\downarrow$ & 269 \\
\hline
\end{tabular}

decreased cell-cell adhesion, transmits signals which actively promote tumor-cell invasion and metastasis. ${ }^{82}$ Likewise, activated MMP-9 enhances the invasion of the cultured cells by degrading ECM. ${ }^{83}$ Moreover, CHI3L1 inhibits IL-1-induced and TNF-a-induced secretion of MMPs (MMP-1, MMP-3, and MMP-13), which depends on the reduced activation of the p38 and SAPK/JNK pathways. ${ }^{84}$ The expression of MMP-1, MMP-3, and MMP-13 has been primarily detected in cartilage, where CHI3L1 targets and degrades proteoglycan, collagen, osteonectin, and perlecan to facilitate the progression of osteoarthritis (OA) ${ }^{85}$ The expression and enzymatic activity of MMP-2 has been reported to be markedly reduced in $\mathrm{CHI} 3 \mathrm{~L} 1$-silenced glioma cells. ${ }^{41}$ MMP-2 localization on the surface of invasive cells facilitates cell invasion by regulating matrix degradation and motility. ${ }^{86}$ Overall, CHI3L 1 plays a crucial role in ECM regulation, which has a large impact on tissue remodeling and invasive cancer progression.

\section{SPECIFIC RECEPTORS, LIGANDS, AND INTERACTING COMPLEXES OF CHI3L1}

IL-13Ra2

IL-13Ra2, also known as CD213A2 and cancer/testis antigen 19 (CT19), is a glycosylated transmembrane protein which is highly expressed in several cancer types including glioblastoma, ${ }^{87}$ breast cancer, ${ }^{88}$ ovarian carcinoma, ${ }^{89}$ and colorectal cancer. ${ }^{90}$ It has been successfully applied as a therapeutic target of chimeric antigen receptor (CAR)-engineered $T$ cells in a patient with recurrent multifocal glioblastoma. ${ }^{91}$ IL-13Ra2 has a short cytoplasmic motif that lacks the conserved box 1 region necessary for signal transduction. IL-13 binds IL-13Ra2 with high affinity and acts as a decoy receptor to inhibit response to IL-13 through the IL-13Ra1/ IL-4Ra heterodimer. ${ }^{92,93}$

CHI3L1 forms a multimeric complex with IL-13Ra2 and IL-13 to activate the MAPK/Erk, Akt, and Wnt/ $\beta$-catenin cell signaling pathways to regulate apoptosis, oxidant injury-induced cell death, Streptococcus pneumonia-induced macrophage pyroptosis and inflammasome activation, antibacterial response, and melanoma metastasis. $^{18}$ A recent study reveals that $\mathrm{N}$-glycosylation is a critical determinant of $\mathrm{CHI}$ L1 1 and IL-13 binding to IL-13Ra2. ${ }^{94}$ CHI3L1 and IL-13 do not compete for IL-13Ra2 binding and signaling, and they do not bind to identical locations on IL-13Ra2. The elimination of IL-13Ra2 partially abrogates specific CHI3L1 effector responses, suggesting the presence of other receptors ${ }^{18}$ (Fig. 2).

\section{TMEM219}

TMEM219, also known as insulin-like growth factor-binding protein 3 receptor (IGFBP-3R), is a protein that acts as a cell death receptor for IGFBP-3 in breast and prostate cancers. ${ }^{95}$ It has been identified as a binding partner for IL-13Ra2 in the formation of the CHI3L1-IL-13Ra2-TMEM219 complex. $^{30}$ The affinity of IL-13 with IL-13Ra2 has been reported to increase in the presence of TMEM219, which does not bind to IL-13Ra2. On CHI3L1 stimulation, TMEM219 enhances the expression of heparin-binding EGF-like growth factor (HB-EGF) on epithelial cells and macrophages through the activation of the MAPK/Erk and PKB/Akt pathways ${ }^{30}$ (Fig. 2).

\section{Galectin-3}

The $\beta$-galactoside-binding protein Gal-3 is expressed at high levels in the nucleus, cytoplasm, and extracellular milieu of cells including lung epithelial cells. ${ }^{96}$ Gal-3 physically interacts with IL-13Ra2 and CHI3L1 to compete with TMEM219 for IL-13Ra2 binding and diminish the anti-apoptotic role of CHI3L1. ${ }^{31}$ Upon accumulation in the extracellular space, Gal-3 drives the apoptosis of primary lung epithelial cells. Conversely, the intracellular expression of Gal-3 has a dominating influence on M2 macrophage differentiation and myofibroblast proliferation, thereby contributing to exaggerated injury and fibroproliferative repair responses in Hermansky-Pudlak syndrome (HPS) ${ }^{31}$ (Fig. 2).

Chemoattractant receptor-homologous molecule expressed on Th2 cells (CRTH2)

$\mathrm{CHI}$ L1 interacts with the prostaglandin D2 receptor $\mathrm{CRTH} 2$ to enhance collagen accumulation in HPS1 mutant cells and promote the lung tissue fibrotic response. In HPS patients, the membrane expression of IL-13Ra2 is decreased. ${ }^{97}$ In normal individuals, however, CHI3L1 ameliorates epithelial cell apoptosis and lung injury in an IL-13Ra2-dependent manner.

\section{CD44}

CD44, a cell-surface transmembrane glycoprotein, has been recognized as a key signaling regulator of cell growth, survival, and differentiation. ${ }^{98}$ Recently, our group reported that CHI3L1 physically interacts with CD44 to activate the Erk and Akt pathways, along with phosphorylation of $\beta$-catenin at Ser552 and Ser675. ${ }^{32}$ Interestingly, CD44v3 peptide and protein, but neither CD44v6 peptide nor CD44s protein, bound to CHI3L1. We showed high CHI3L1 expression levels in GC tissues and patient sera that significantly correlated with GC progression. Mechanistically, CHI3L1 promoted GC cell growth, proliferation, and 


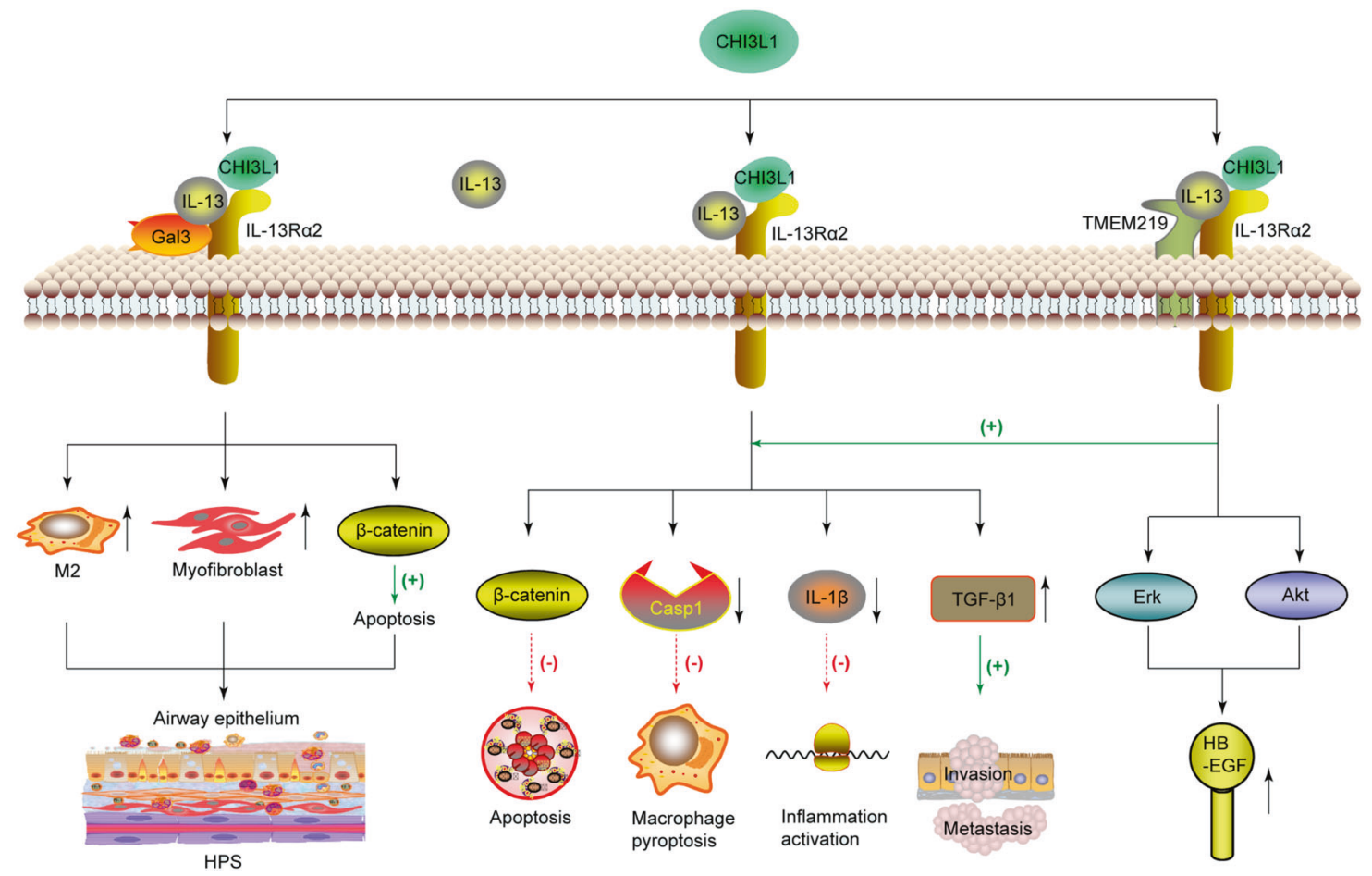

Fig. 2 CHI3L1 interacts with IL-13-IL-13R 2 to form a multimeric complex, and synergistically interacts with TMEM219 and Gal-3, respectively. CHI3L1 binds IL-13R $\alpha 2$ to activate the Erk, Akt, and Wnt/ $\beta$-catenin pathways to regulate apoptosis, pyroptosis, inflammasome activation, antibacterial responses, and malignancy metastasis. The binding ability of IL-13 with IL-13R $\alpha 2$ is increased in the presence of TMEM219, thereby enhancing the anti-apoptosis response induced by CHI3L1 stimulation. Gal-3 interacts with CHI3L1-IL-13-IL-13R 2 complex to compete with TMEM219 for IL-13R 22 binding to diminish the anti-apoptotic role of CHI3L1. HPS Hermansky-Pudlak syndrome, HB-EGF heparin-binding EGF-like growth factor

metastasis via CHI3L1-CD44 interaction and cascade signaling pathway activation $^{32}$ (Fig. 3).

\section{Heparin}

CHI3L1 harbors a putative heparin-binding motif consisting of positively charged arginine (R) and lysine (K) (RRDK; residues 144-147). ${ }^{99}$ However, an X-ray crystallographic analysis of CHI3L1 suggested the lack of heparin-binding affinity in the amino acid-rich motif. ${ }^{43}$ A KR-rich domain (residues 334-345) in the C-terminus, rather than the typical RRDK domain, was identified as the functional domain responsible for heparin binding, and the biological activity of CHI3L1. ${ }^{100} \mathrm{CHI} 3 \mathrm{~L} 1$ interacts with other heparin-like molecules such as heparin sulfate (HS) in the ECM or on the cell surface, which is of paramount importance in cell differentiation, adhesion, proliferation, migration, growth factor and cytokine action, tissue morphogenesis and organogenesis, and tissue injury and remodeling. ${ }^{99}$ Syn-1, an integral membrane protein distributed on the cell surface and in the ECM, is the primary source of cell-surface HS. ${ }^{101}$ Consequently, CHI3L1 induces the coordination between the receptor Syn-1 and the integrin $a_{v} \beta_{3}$, which binds to the HS chain in the ectodomain of Syn-1, triggering FAK $^{861}$ and MAPK/Erk1/2 signaling pathways to enhance the cancer cell growth and produce the endothelial cell angiogenic signature. ${ }^{34} \mathrm{CHI}$ L1 also induces the coordination of Syn- 1 and integrin $a_{v} \beta_{5}$, phosphorylating $F^{2} K^{397}$ and Erk $1 / 2$ to upregulate VEGF and enhance angiogenesis ${ }^{102}$ (Fig. 4).

\section{Chitin}

Chitin, a glucose derivative, is the primary structural component of cell walls of plants, algae, fungi, and bacteria; the microfilarial sheath of parasitic nematodes; the radulae of molluscs; cephalopod beaks; fish scales; and lissamphibians. ${ }^{103,104}$ CHI3L1 lacks chitinase/hydrolase activity and strongly binds to chitin. ${ }^{2}$ The binding of chitin fragments to $\mathrm{CHI} 3 \mathrm{~L} 1$ relies on the length of the oligosaccharide. Chitin disaccharides tend to occupy the distal subsites, while longer chitin fragments always occupy the central subsites in the groove. ${ }^{43}$ The absence of enzymatic activity in CHI3L1 is ascribed to a single-residue substitution in the chitinase3-like catalytic domain, in which an essential glutamic acid is replaced by leucine. ${ }^{43}$ Although chitin has not been identified in mammals to date, it is likely that CHI3L1 interacts with other endogenous substances containing chitin-like motifs.

Hyaluronic acid

Hyaluronic acid, an anionic and non-sulfated glycosaminoglycan, is widely distributed throughout epithelial, connective, and neural tissues. As one of the chief components of the ECM, hyaluronic acid contributes significantly to inflammation, ${ }^{105}$ wound healing, ${ }^{106}$ granulation tissue formation, ${ }^{107}$ proliferation, and migration. ${ }^{108} \mathrm{CHI} 3 \mathrm{~L} 1$, along with hyaluronic acid, is increasingly being acknowledged as an effective, non-invasive biomarker for the diagnosis of hepatic fibrosis. ${ }^{109}$ The amino-acid sequence analysis indicated that $\mathrm{CHI} 3 \mathrm{~L} 1$ contains two potential hyaluronic acidbinding motifs (residues 147-155 and 369-377) on the external face of the folded protein, but this warrants further evaluation using crystallization studies. ${ }^{66,99}$

\section{Collagen}

Affinity chromatography experiments on purified CHI3L1 have demonstrated that it binds all three forms of collagen-types I, II, and III-specifically. ${ }^{110}$ The binding of the chondrocyte-derived species to type I collagen has been demonstrated by surface plasmon resonance analysis and blocking assays. ${ }^{110}$ However, the roles of these interactions require further investigation. 


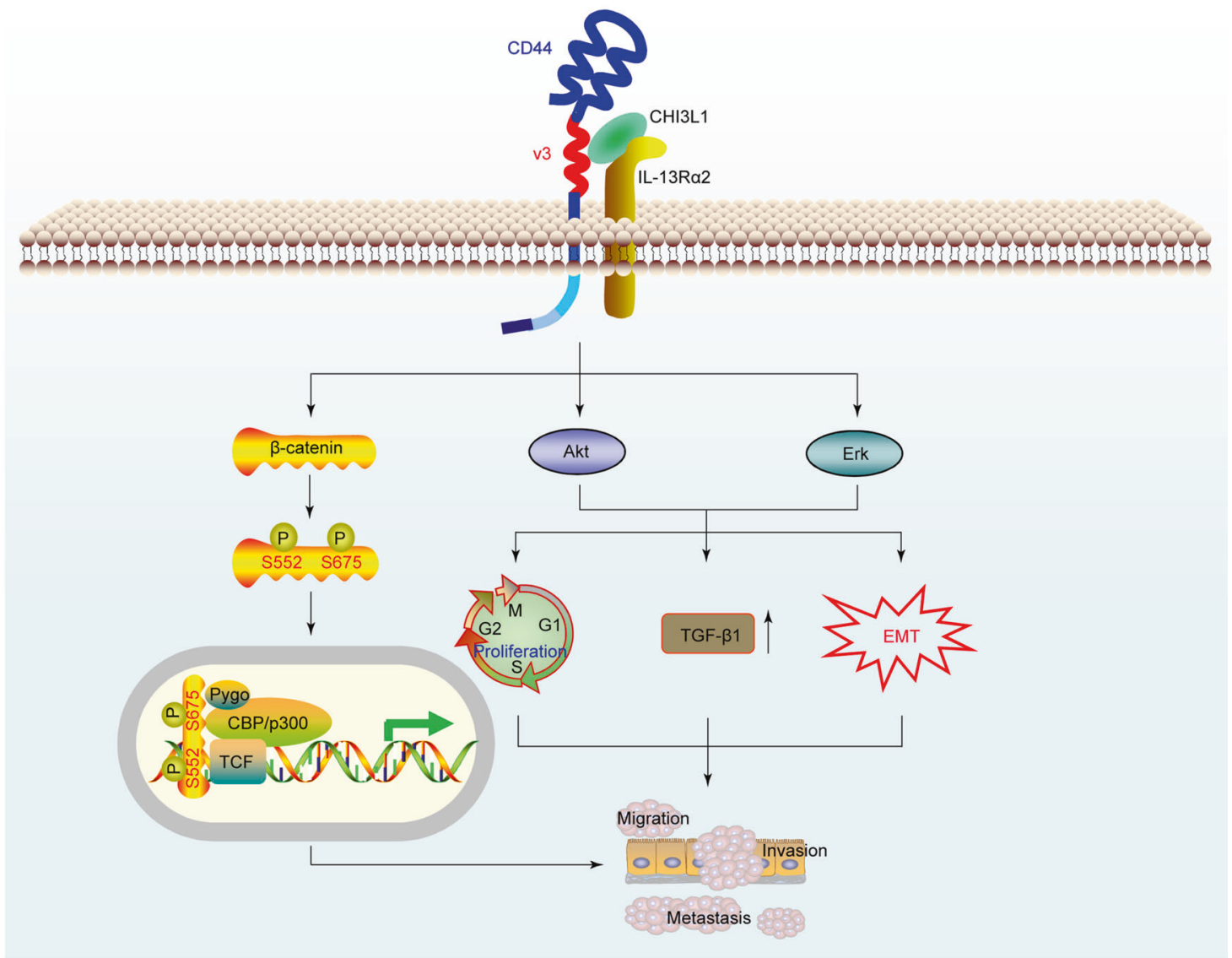

Fig. 3 CHI3L1 physically interacts with the CD44 to promote GC invasion and metastasis. CHI3L1 is highly expressed in GC tissues and patient sera, and interacts with CD44v3 to activate the Akt, Erk, and $\beta$-catenin signaling pathways, contributing to GC progression

\section{CHI3L1 IN ONCOGENESIS}

CHI3L1 is overexpressed in a multitude of human cancers and animal tumor models (Table 2). Moreover, elevated levels of $\mathrm{CHI}$ L1 have been strongly correlated with stages and outcomes of multiple types of primary and secondary carcinomas including oligodendroglia, glioblastoma, osteosarcoma, acute myeloid leukemia, sarcoma, Hodgkin lymphoma, germ-cell, lung, uterine, ovarian, bladder, prostate, kidney, colon, and GCs. ${ }^{20,22-24,111-116}$ As shown in Fig. 5, we analyzed the data from GEPIA (http://gepia. cancer-pku.cn) and found that CHI3L1 level is significantly increased in tumors including bladder urothelial carcinoma (BLCA), colon adenocarcinoma (COAD), glioblastoma multiforme (GBM), ovarian serous cystadenocarcinoma (OV), pancreatic adenocarcinoma (PAAD), rectum adenocarcinoma (READ), stomach adenocarcinoma (STAD), thyroid carcinoma (THCA), and uterine corpus endometrial carcinoma (UCEC). Importantly, increased CHI3L1 level is in significantly associated with poor prognosis and known to affect the survival of patients suffering from a variety of tumors including breast cancer, bladder cancer, lung squamous cell carcinoma, ovarian cancer, GC, sarcoma, and glioma, as analyzed from KMplot (https://kmplot.com) and CGGA (http://www.cgga.org.cn) website (Fig. 6).

CHI3L1 promotes cancer cell growth, proliferation, invasion, and metastasis

CHI3L1 stimulation results in the phosphorylation of Erk1/2 in 293 cells, U373 cells, and U87 MG cells, thereby leading to proliferation. ${ }^{117}$ Similarly, a recombinant $\mathrm{CHI} 3 \mathrm{~L} 1$ was reported to significantly enhance the proliferation of SW480 cells, through the activation of MAPK/Erk signaling pathway. ${ }^{29}$ Furthermore, CHI3L1 significantly promotes the proliferation and migration of colon cancer cells, including SW480 and COLO 205 cells, through the NF-KB signaling pathway. ${ }^{118} \mathrm{CHI}$ L1 1 also induces the expression of pro-inflammatory and pro-tumorigenic molecules, including CCL2, CXCL2, MMP-2, and MMP-9, which contribute to tumor cell growth and proliferation. ${ }^{28}$ Interestingly, the presence of $\mathrm{CHI} 3 \mathrm{~L} 1$ in the allergen-induced inflammatory lung attracts myeloid cells, which produce pro-tumorigenic cytokines for tumor growth and metastasis. ${ }^{119}$

Metastasis and invasion are essential hallmarks and leading causes of death in patients with aggressive forms of cancer. ${ }^{120}$ Between $39 \%$ and $91 \%$ of patients with metastases exhibit elevated serum levels of $\mathrm{CHI} 3 \mathrm{~L} 1 i^{121}$ and patients overexpressing $\mathrm{CHI} 3 \mathrm{~L} 1$ show higher tumor metastasis and poor survival. Consequently, CHI3L1 has been proposed as a prognostic biomarker for neoplastic diseases including papillary THCA, breast cancer, prostate carcinoma, lung cancer, and hepatocellular carcinoma. ${ }^{22,73,122,123}$ Previous studies have shown that CHI3L1 induces the directional migration of endothelial cells. ${ }^{66}$ Consistently, CHI3L1 has been characterized by its ability to promote cancer metastasis and invasion in a variety of tumor types including glioblastoma (U87MG), prostate cancer (C4-2B), and cervical cancer (CaSki and HeLa). ${ }^{41,124,125}$ The epithelial-mesenchymal transition (EMT), a key developmental program which generates cells possessing the properties of stem cells, is often activated during cancer metastasis and invasion. ${ }^{126}$ In the non-small cell lung cancer (NSCLC) cell lines CL1-1, H23, H838, CL1-5, and H2009, CHI3L1 regulates the expression of EMT markers including Twist, Snail, Slug, N-cadherin, vimentin, and E-cadherin, ${ }^{127}$ which indicates that CHI3L1 is a major factor in NSCLC metastasis. Likewise, CHI3L1 expression has been positively correlated with the motility and invasiveness of prostate cancer cells (DU145 and 


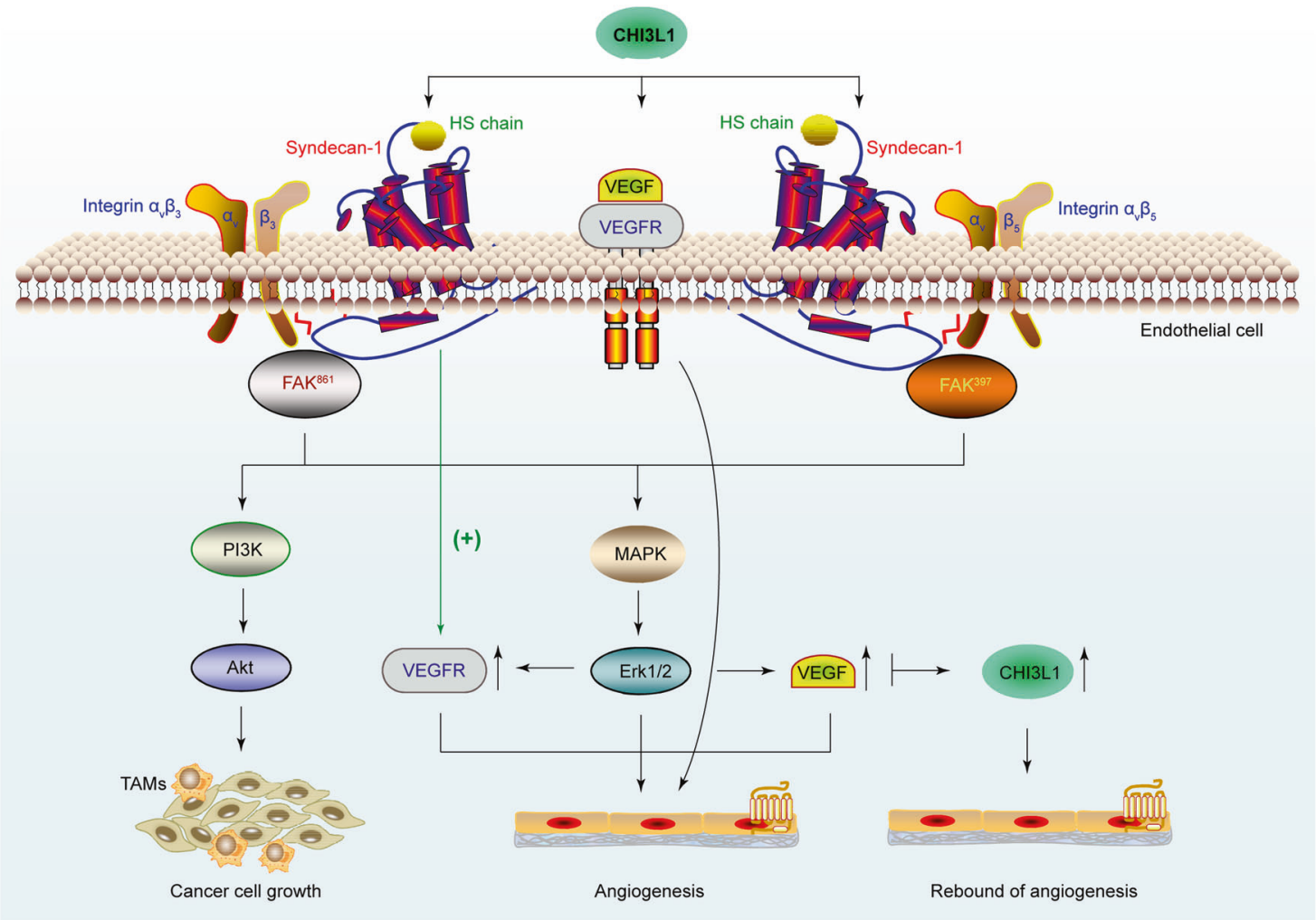

Fig. $4 \mathrm{CHI} 3 \mathrm{~L} 1$ induces angiogenesis and cancer cell proliferation to facilitate glioblastoma progression. CHI3L1 binds the HS chain of Syn-1 to induce coordination between Syn- 1 and the integrin $\alpha_{v} \beta_{3}$, triggering the FAK ${ }^{861}$ and MAPK/Erk $1 / 2$ and PI3K signaling pathways to produce the endothelial cell angiogenic signature. Similarly, CHISL1 induces coordination between Syn-1 and integrin $\alpha_{v} \beta_{5}$ to activate FAK ${ }^{397}$ and downstream signaling pathways, upregulating VEGF. Interestingly, sustained inhibition of VEGF finally upregulates CHI3L1 expression, which contributes to anti-VEGF resistance and invasiveness

Table 2. CHI3L1 is overexpressed in certain cancer types

\begin{tabular}{|c|c|c|}
\hline Systems & Tumor types & References \\
\hline \multirow[t]{5}{*}{ Reproductive system } & Breast cancer & $23,28,119,150,237,238,270-272$ \\
\hline & Ovarian cancer & $115,239,240$ \\
\hline & Cervical cancer & $125,139,273$ \\
\hline & Endometrial cancer & $274-276$ \\
\hline & Prostatic cancer & $22,124,277,278$ \\
\hline \multirow[t]{3}{*}{ Digestive system } & Gastric cancer & $32,113,150$ \\
\hline & Hepatic carcinoma & $279-281$ \\
\hline & Colon cancer & $21,29,114,118,282,283$ \\
\hline \multirow[t]{2}{*}{ Central nervous system } & Glioblastoma & $6,41,111,258,284-287$ \\
\hline & Astrocytoma & 62 \\
\hline \multirow[t]{2}{*}{ Hematologic system } & $\begin{array}{l}\text { Acute myeloid } \\
\text { leukemia }\end{array}$ & 20 \\
\hline & Hodgkin lymphoma & 112 \\
\hline \multirow[t]{2}{*}{ Motor system } & Osteosarcoma & 288 \\
\hline & Multiple myeloma & 289 \\
\hline Respiratory system & Lung cancer & $4,24,121,290$ \\
\hline Urinary system & Renal carcinoma & 274 \\
\hline Others & Melanoma & $27,291-293$ \\
\hline
\end{tabular}

PC3), where it directly affects cancer metastasis by regulating the expression of EMT genes. ${ }^{128}$ Both ECM degradation and reduction in cell-ECM adhesion contribute to malignant transformation and local invasiveness. MMP-2, regarded as an initiator of tumor metastasis, acts by breaking down the ECM, promoting the migration of cancer cells. ${ }^{129}$ CHI3L1 knockdown reduces MMP-2 gene expression and affects the adhesiveness of U87 MG cells to ECM remarkably. ${ }^{41}$

CHI3L1 favors angiogenesis and vasculogenic mimicry (VM) formation in tumors

Angiogenesis, a crucial part of solid tumor development, supplies oxygen and other essential nutrients in a relatively hypoxic microenvironment found at the center of growing neoplasms, facilitating tumor cell proliferation by enhancing oxygenation. ${ }^{130}$ CHI3L1 has been shown to stimulate the directional migration of umbilical vein endothelial cells (HUVEC), which provided the first significant evidence that CHI3L1 functions in tumor angiogenesis by stimulating the reorganization and migration of vascular endothelial cells. ${ }^{66}$ Currently, CHI3L1 is increasingly acknowledged as an angiogenic stimulator, which promotes tumor angiogenesis through VEGF-dependent and VEGFindependent pathways. ${ }^{102,131,132}$

VEGF, a vital signaling protein involved in both vasculogenesis and angiogenesis, has been shown to be one of the most potent mediators of angiogenesis in tumor initiation and promotion. ${ }^{133}$ Serum levels of CHI3L1 correlate with VEGF expression and microvessel density in tumor tissues in a VEGF-dependent manner, which promotes angiogenesis and is responsible for cancer progression. ${ }^{125} \mathrm{CHI}$ L1 also influences the coordination between Syn- 1 and integrin $a_{v} \beta_{5}$, thereby upregulating VEGF and enhancing angiogenesis through the phosphorylation of $\mathrm{FAK}^{397}$ and Erk1/2. ${ }^{102}$ CHI3L1-induced angiogenesis results from the coordination between integrin $\alpha_{v} \beta_{3}$ and Syn-1, which triggers the FAK $^{861}$ and MAPK/Erk1/2 signaling pathways in a VEGFindependent manner in MDA-MB-231 breast cancer and HCT116 colon cancer cells. ${ }^{34}$ Alternatively, CHI3L1 enhances the 

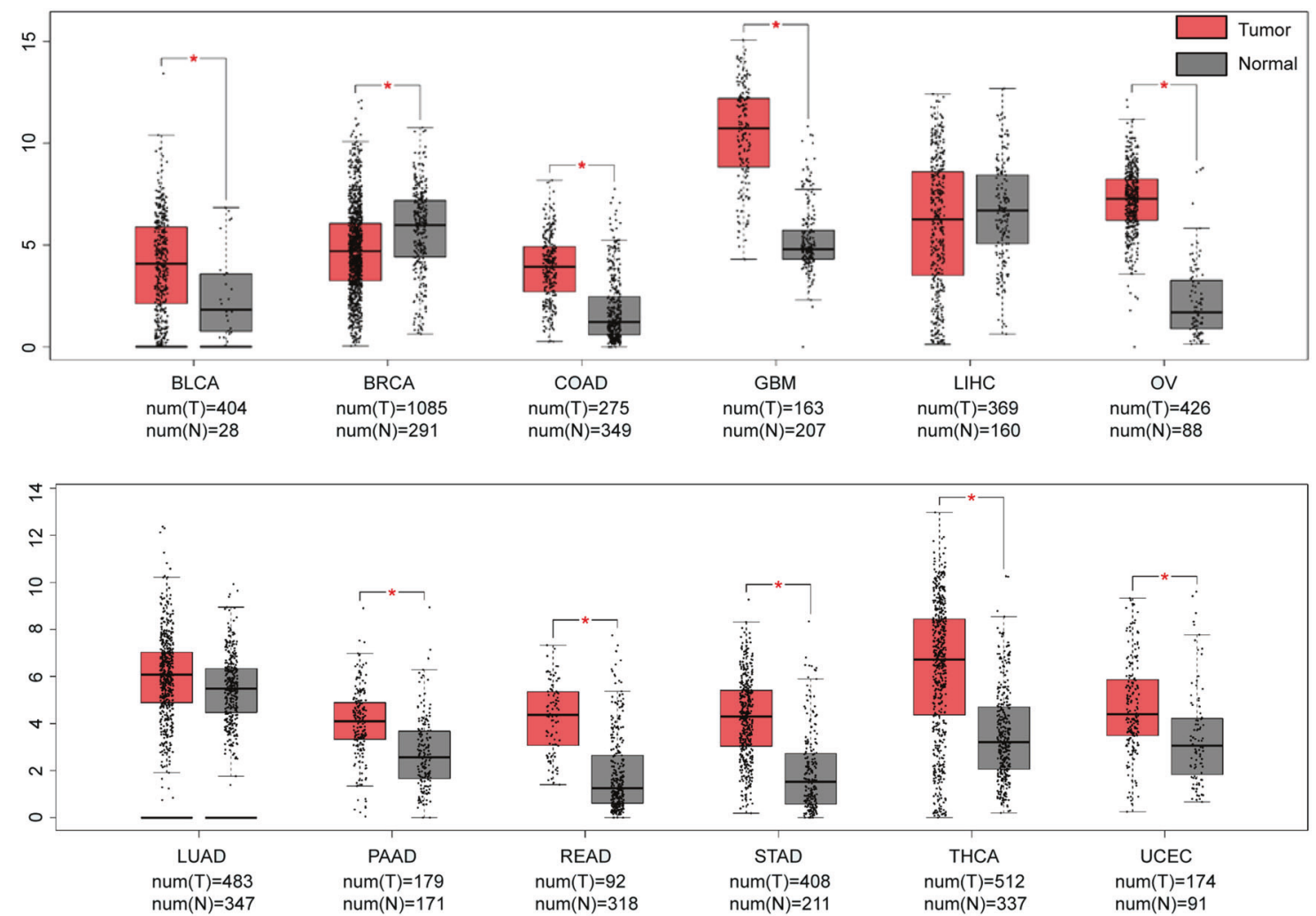

Fig. $5 \mathrm{CHI}$ L1 is overexpressed in certain cancer types. The level of CHI3L1 is significantly overexpressed in tumors including BLCA, COAD, GBM, OV, PAAD, READ, STAD, THCA, and UCEC. However, it is downregulated in BRCA, and shows no difference among LIHC and LUAD (from http://gepia.cancer-pku.cn). ${ }^{*} p<0.05$. BLCA bladder urothelial carcinoma, BRCA breast invasive carcinoma, COAD colon adenocarcinoma, GBM glioblastoma multiforme, LIHC liver hepatocellular carcinoma, LUAD lung adenocarcinoma, OV ovarian serous cystadenocarcinoma, PAAD pancreatic adenocarcinoma, READ rectum adenocarcinoma, STAD stomach adenocarcinoma, THCA thyroid carcinoma, UCEC uterine corpus endometrial carcinoma

production of pro-angiogenic molecules like CCL2, CXCL2, and MMP-9 in the pulmonary infiltrating macrophages of mammary tumor-bearing mice. ${ }^{134}$

VM is an alternative microvascular system that exhibits high aggressiveness and genetically dysregulates tumor cell orchestration. ${ }^{135}$ It facilitates tumor perfusion and promotes distant metastasis, in the absence of angiogenesis, in highly malignant cancers including melanoma, ${ }^{136}$ small cell lung cancer, ${ }^{137}$ and glioblastoma. ${ }^{138}$ Recently, the expression of CHI3L1 in cervical cancer tissues was shown to be positively associated with VM formation, with CHI3L1 directly stimulating the formation of vessel-like structures in vitro in cervical cancer cells. ${ }^{139}$ However, the mechanism underlying the induction of VM formation by $\mathrm{CHI}$ L1 requires further investigation.

CHI3L1 drives tumor-associated inflammation Inflammation is increasingly regarded as one of the hallmarks of cancer. ${ }^{140}$ Inflammatory responses at metastatic sites supply abundant bioactive molecules to the tumor microenvironment including growth factors, survival factors, pro-angiogenic factors, and ECM-modifying enzymes that facilitate invasion and metastasis, and inductive signals that switch on the activation of EMT. ${ }^{141-143}$ Moreover, infiltrating inflammatory cells like TAMs, $\mathrm{T}$ cells, and myeloid-derived cells promote angiogenesis and accelerate EMT around the tumor lesion. ${ }^{144}$

CHI3L1 knockout tumor bearers with pre-existing allergeninduced pulmonary inflammation show decreased proinflammatory mediator secretion, significantly decreased populations of myeloid-derived cells, reduction in tumor volume, reduced lung metastases, and increased survival relative to wildtype controls. ${ }^{119}$ An investigation exploring the role of CHI3L1 in "pre-metastatic" lungs revealed that $\mathrm{CHI} 3 \mathrm{~L} 1$ induced the expression of pro-angiogenic molecules including CCL2, CXCL2, and MMP-9 in macrophages to facilitate the incidence of pulmonary metastasis. ${ }^{134}$ In vitro, CHI3L1 efficiently enhanced the secretion of IL-8 and TNF-a from SW480 cells by activating the NF-KB signaling pathway, thereby promoting cancer cell proliferation and migration. ${ }^{118,145}$ Additionally, CHI3L1 stimulation increased the expression of IL- 8 and CCL2 by SW480 cells via the activation of the MAPK cascade pathway. ${ }^{29}$ Mechanistically, residues 325-339 of the carbohydrate-binding motif of CHI3L1 specifically bind to IL-8 promoters and enhance IL-8 production in SW480 cells via the phosphorylation of Akt. ${ }^{145}$ IL-8, MMP-2, MMP-9, CCL2, and CXCL2, along with other proinflammatory mediators at the tumor site, favor tumor progression by promoting angiogenesis, accelerating ECM degradation, providing sustained survival signals to cancer stem cells, and recruiting immunosuppressive myeloid cells. ${ }^{146,147}$

The expression of $\mathrm{CHI} 3 \mathrm{~L} 1$ has been significantly associated with the migration of THP-1 cells and the infiltration of TAMs in colon cancer. ${ }^{29}$ Mechanistically, CHI3L1 promotes macrophage recruitment through the MAPK (particularly Erk and JNK) signaling pathway in cancer cells to secrete inflammatory chemokines, primarily IL-8 and CCL2. ${ }^{29}$ Specialized subpopulations of macrophages, key components in the tumor microenvironment, facilitate cancer cell growth, proliferation, invasion, and metastasis, while inhibiting antitumor immunity. ${ }^{143}$ Upon recruitment and activation, CHI3L1 induces M2 macrophage (alternatively activated) differentiation by the phosphorylation of Erk. ${ }^{19,148}$ Conversely, CHI3L1 is highly expressed in $S$. aureus-stimulated macrophages, where it promotes $\mathrm{M} 1$ polarization of macrophages (classically activated) via activation of the MAPK pathway. ${ }^{149}$ Mechanistically, CHI3L1 secreted from M2 macrophages interacts 

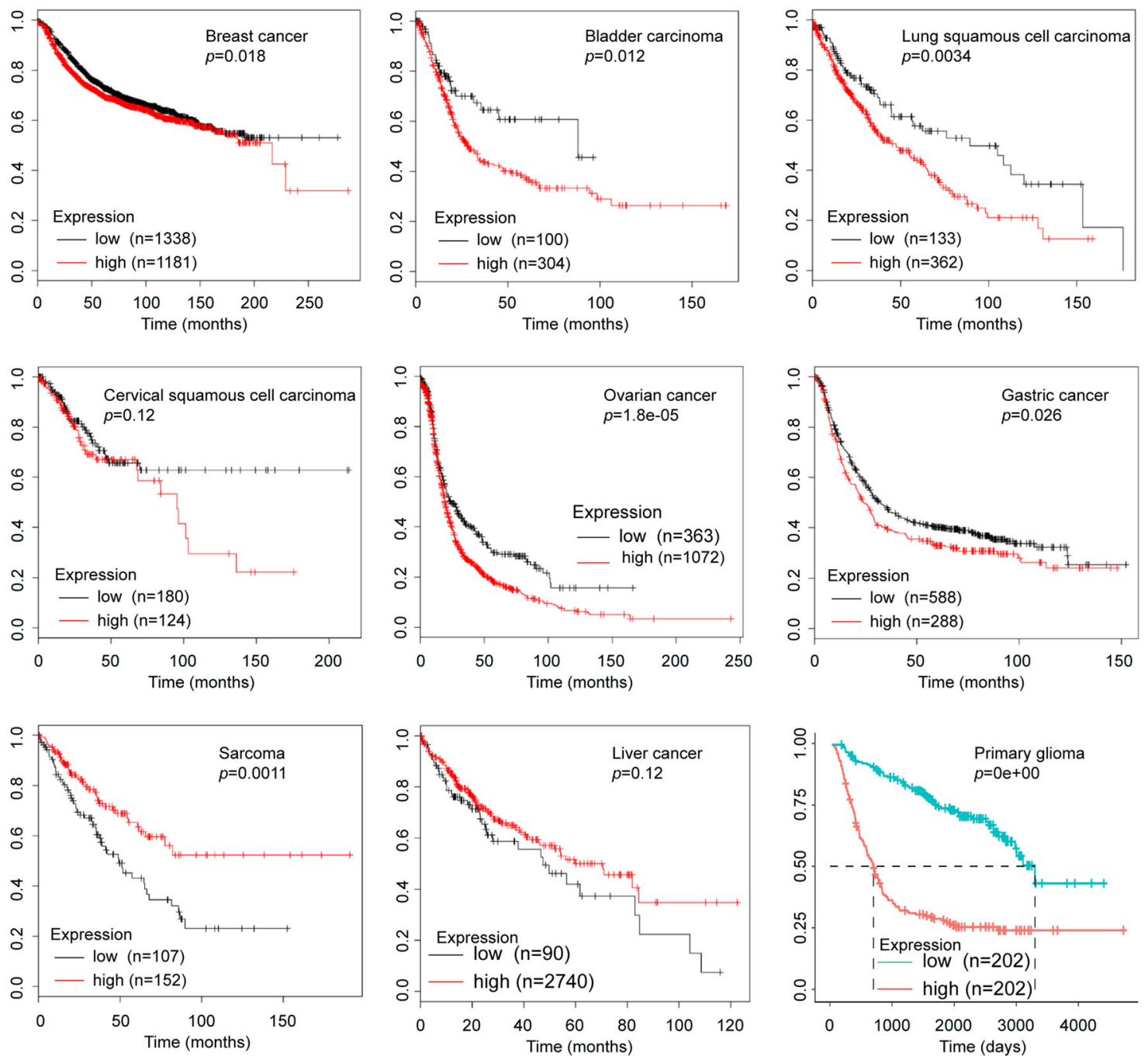

Fig. 6 Elevated expression CHI3L1 is inversely correlated with the survival of patients with malignancy. CHI3L1 is overexpressed in patients with breast cancer, bladder carcinoma, lung squamous cell carcinoma, ovarian cancer, gastric cancer, and glioma, and is associated with lower survival rates. Conversely, no relationship is found between CHI3L1 overexpression and survival in patients with cervical squamous cell carcinoma and liver cancer, while a negative correlation was observed between among patients bearing sarcoma. (from https://kmplot.com, http://www.cgga.org.cn)

with IL-13Ra2 on the plasma membrane of cancer cells, triggering the activation of the MAPK signaling pathway in GC and breast cancer. ${ }^{150}$ Upon activation, Erk and JNK signaling enhances the expression of MMPs, which degrade the ECM in the tumor microenvironment, thereby facilitating metastasis. ${ }^{151}$ Accordingly, CHI3L1 induces MMP-9 production by macrophages and enhances matrix degradation in triple-negative breast cancer mouse models. ${ }^{152}$ Moreover, the deletion or targeted inhibition of $\mathrm{CHI} 3 \mathrm{~L} 1$ enhances Th1 effector cytokine (IFN- $\gamma$, TNFa) production and CTL response to enhance anti-tumor immunity and reduce pulmonary metastasis. $^{73}$

\section{CHI3L1 IN NON-CANCEROUS DISEASES}

CHI3L1 also played critical roles in the pathogenesis of noncancerous diseases. A recent study followed prospectively 94,665 individuals from the Danish general population for up to 23 years and analyzed for plasma CHI3L1 levels $(n=21,584)$ and CHI3L1 rs4950928 genotype $(n=94,184)$, and reveals that baseline elevated plasma CHI3L1 is not a cause, but a strong marker of increased risk of future infectious diseases in individuals in the general population. ${ }^{153}$ The roles of $\mathrm{CHI} 3 \mathrm{~L} 1$ are further summarized according to the organ systems of the human body in Table 3.

\section{RESPIRATORY DISEASES}

Inflammation

Elevation of CHI3L1 level is induced by inflammations in lungs. The causes behind inflammation include cigarette smoke, ${ }^{33}$ virus, $^{154}$ and bacterial ${ }^{16}$ infection. CHI3L1 regulates M2 macrophage activation and Th2 immune response during RSV infection. ${ }^{154}$ CHI3L1 also promotes Streptococcus pneumoniae bacteria clearance by inhibiting caspase-1-dependent macrophage pyroptosis, and augments host tolerance to lung antibacterial responses by controlling inflammasome activation, ATP accumulation, and production of thymic stromal lymphopoietin and type 1 , type 2 , and type 17 cytokines. $^{16}$ In the absence of CHI3L1, IL-18induced Type 2 and Type 17 inflammation and fibrotic airway remodeling were significantly ameliorated while Type 1 inflammation and emphysematous alveolar destruction were enhanced. ${ }^{155}$ Instead, CHI3L1 increases the expression of MUC5AC, which is the major mucin in the human respiratory tract leading to chronic cough and sputum production in chronic 
Table 3. CHI $3 \mathrm{~L} 1$ in other non-cancerous diseases

\begin{tabular}{|c|c|c|c|}
\hline System & Category & Related factors & Phenomenon and effect \\
\hline \multirow[t]{17}{*}{ Respiratory } & \multirow[t]{7}{*}{ Inflammation } & Cigarette smoke $\mathrm{s}^{33}$ & CHI3L1个 \\
\hline & & $\mathrm{RSV}^{154}$ & $\mathrm{CHI} 3 \mathrm{~L} 1 \uparrow \rightarrow \mathrm{M} 2 \mathrm{M} \Phi$ activation \\
\hline & & IL-18 $8^{155}$ & $\begin{array}{l}\mathrm{CHI} 3 \mathrm{~L} 1 \uparrow \rightarrow \text { Type } 2 \text { and type } 17 \text { inflammation and fibrotic airway } \\
\text { remodeling }\end{array}$ \\
\hline & & Interstitial lung disease ${ }^{157,158}$ & $\mathrm{CHI} 3 \mathrm{~L} 1 \uparrow \rightarrow$ poorer prognosis \\
\hline & & $\begin{array}{l}\text { Chronic inflammatory airway } \\
\text { disease }\end{array}$ & $\mathrm{CHI} 3 \mathrm{~L} 1 \uparrow \rightarrow \mathrm{MUC5} \mathrm{AC} \uparrow$ \\
\hline & & Bacterial infection $^{16}$ & $\mathrm{CHI} 3 \mathrm{~L} 1 \uparrow \rightarrow$ bacterial clearance \\
\hline & & Hypersensitivity pneumonitis ${ }^{156}$ & $\mathrm{CHI} 3 \mathrm{~L} 1 \uparrow \rightarrow$ poorer prognosis \\
\hline & \multirow[t]{3}{*}{ Ashma } & High fat $\operatorname{diet}^{74}$ & CHISL1 $\uparrow \rightarrow$ WAT accumulation and lung Th2 inflammation \\
\hline & & Bronchial remodeling ${ }^{33}$ & $\begin{array}{l}\mathrm{CHI} 3 \mathrm{~L} 1 \uparrow \rightarrow \text { bronchial smooth muscle cell proliferation and } \\
\text { migration }\end{array}$ \\
\hline & & $\begin{array}{l}\text { Asthma status and lung } \\
\text { function }{ }^{159-162}\end{array}$ & $\mathrm{CHI} 3 \mathrm{~L} 1 \uparrow \rightarrow$ asthma $\uparrow$, lung function $\downarrow$ \\
\hline & \multirow[t]{4}{*}{ Lung fibrosis } & Idiopathic pulmonary fibrosis ${ }^{163}$ & CHI3L1 $\uparrow \rightarrow$ injury $\downarrow$ profibrotic effect $\uparrow$ \\
\hline & & Hermansky-Pudlak syndrome ${ }^{31,97}$ & $\mathrm{CHI} 3 \mathrm{~L} 1 \uparrow \rightarrow$ pulmonary fibrosis $\uparrow$ \\
\hline & & Cystic fibrosis ${ }^{164}$ & $\mathrm{CHI} 3 \mathrm{~L} 1 \uparrow \rightarrow$ exacerbations $\uparrow$ \\
\hline & & Asbestosis $^{165}$ & $\mathrm{CHI} 3 \mathrm{~L} 1 \uparrow \rightarrow$ lung function $\downarrow$ \\
\hline & \multirow[t]{2}{*}{ Lung injury } & Hyperoxia ${ }^{30,269}$ & CHI3L $1 \downarrow \rightarrow$ acute lung injury $\uparrow$ \\
\hline & & Oxidant-induced ${ }^{30}$ & $\mathrm{CHI} 3 \mathrm{~L} 1 \uparrow \rightarrow$ oxidant-induced apoptosis and lung injury \\
\hline & COPD & Status and airway remodeling ${ }^{166,167}$ & $\mathrm{CHI} 3 \mathrm{~L} 1 \uparrow \rightarrow$ exacerbations $\uparrow, \mathrm{M} \Phi$ activation $\uparrow$ \\
\hline \multirow[t]{10}{*}{ Digestive } & \multirow[t]{4}{*}{ Liver injury } & $\operatorname{ConA}^{168}$ & CHI3L1 $\rightarrow$ liver injury $\uparrow$ \\
\hline & & APAP $^{169}$ & $\mathrm{CHI} 3 \mathrm{~L} 1 \rightarrow$ liver damage $\downarrow$ \\
\hline & & Alcohol $^{170}$ & CHI3L1 $\rightarrow$ liver injury $\uparrow$ \\
\hline & & Ischemia-reperfusion ${ }^{171}$ & CHI3L1 $\rightarrow$ liver injury $\uparrow$ \\
\hline & \multirow[t]{4}{*}{ Liver fibrosis } & Hepatitis C & $\begin{array}{l}\text { CHI3L } 1 \uparrow \rightarrow \text { fibrosis rate } \uparrow, \text { TGF- } \beta \uparrow ; ;^{172} \text { Promoter polymorphism is not } \\
\text { associated with disease progression; }{ }^{175} \mathrm{CHI} 3 \mathrm{~L} 1 \uparrow \rightarrow \text { false-positive } \\
\text { rates; } ;^{176} \mathrm{CHI} 3 \mathrm{~L} 1 \uparrow \rightarrow \text { Rapid fibrosis progression after liver } \\
\text { transplantation; }{ }^{173} \mathrm{CHI} 3 \mathrm{~L} 1 \uparrow \rightarrow \text { steatosis } \uparrow^{174}\end{array}$ \\
\hline & & Hepatitis $B^{177-180}$ & Serum $\mathrm{CHI} 3 \mathrm{~L} 1 \uparrow \rightarrow$ liver fibrosis \\
\hline & & Alcoholic liver disease ${ }^{181,182}$ & CHI3L1 $\uparrow \rightarrow$ liver fibrosis \\
\hline & & Non-alcoholic fatty liver disease ${ }^{183}$ & $\mathrm{CHI} 3 \mathrm{~L} 1 \uparrow \rightarrow$ liver fibrosis \\
\hline & \multirow[t]{2}{*}{ Bowel diseases } & IBD & $\begin{array}{l}\text { Fecal CHI3L1 } \rightarrow \text { mucosal inflammation }{ }^{184} \text { and endoscopic } \\
\text { activity }^{185}\end{array}$ \\
\hline & & Colitis & $\begin{array}{l}\text { CHI3L1 binds to bacterial chitin-binding protein, }{ }^{186,187} \text { enhances } \\
\text { bacterial adhesion and invasion, }{ }^{60} \text { activates Akt signaling }{ }^{145} \text { and } \\
\text { IL-6-mediated STAT3 Phosphorylation }\end{array}$ \\
\hline \multirow[t]{12}{*}{ Cardiovascular } & Atherosclerosis & & $\begin{array}{l}\mathrm{CHI} 3 \mathrm{~L} 1 \uparrow \rightarrow \text { coronary }^{189,190} \text { and carotid }{ }^{191} \text { atherosclerosis severity } \uparrow, \\
\text { risk } \uparrow,{ }^{193} \text { exacerbates atherosclerosis }\end{array}$ \\
\hline & $\begin{array}{l}\text { Coronary artery } \\
\text { disease }\end{array}$ & Type $1^{194}$ and type $2^{195}$ diabetes & $\mathrm{CHI} 3 \mathrm{~L} 1 \uparrow$ \\
\hline & Peripheral artery disease & & CHI3L1 $\uparrow \rightarrow$ risk $\uparrow,{ }^{196,197}$ ankle-brachial index $\downarrow^{198}$ \\
\hline & Giant cell arteritis & & CHI3L1 1 in giant cells and macrophages ${ }^{199}$ \\
\hline & Thromboembolism & Venous $^{201}$ and incident ${ }^{200}$ & CHI3L $1 \uparrow$ \\
\hline & \multirow[t]{3}{*}{ Hypertension } & Chinese men 295 & $\mathrm{CHI} 3 \mathrm{~L} 1 \uparrow$ \\
\hline & & $\begin{array}{l}\text { idiopathic pulmonary arterial } \\
\text { Hypertension }\end{array}$ & $\mathrm{CHI} 3 \mathrm{~L} 1 \uparrow$ \\
\hline & & Obstructive sleep apnea (OSA) & CHI3L1 $\uparrow \rightarrow$ endothelial function $\downarrow$ \\
\hline & Atrial fibrillation & & 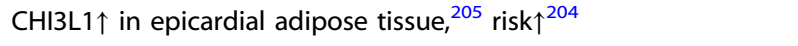 \\
\hline & $\beta$-thalassemia major & Hepatic fibrosis & $\mathrm{CHI} 3 \mathrm{~L} 1 \uparrow^{206}$ \\
\hline & Ischemic heart disease & Type 2 diabetes & $\mathrm{CHI} 3 \mathrm{~L} 1 \uparrow^{195}$ \\
\hline & Chronic heart failure & & $\mathrm{CHI} 3 \mathrm{~L} 1 \uparrow^{207}$ \\
\hline \multirow[t]{3}{*}{ Endocrine } & \multirow[t]{2}{*}{ Diabetes } & Type 2 & $\begin{array}{l}\text { CHI3L } 1 \uparrow^{209} \rightarrow \text { BMI-independent marker, }{ }^{213} \text { albuminuria, }^{211,212} \\
\text { mortality, }_{1}{ }^{214} \text { obesity, }^{210} \text { psychotic disorders }\end{array}$ \\
\hline & & Type 1 & $\mathrm{CHI} 3 \mathrm{~L} 1 \uparrow \rightarrow$ albuminuria ${ }^{215}$ \\
\hline & Obesity & & $\mathrm{CHI} 3 \mathrm{~L} 1 \uparrow^{208}$ \\
\hline
\end{tabular}




\begin{tabular}{|c|c|c|c|}
\hline & Insulin resistance & & $\mathrm{CHI} 3 \mathrm{~L} 1 \uparrow \rightarrow \mathrm{TNF} \alpha$-induced inflammation and insulin resistance $\downarrow^{9}$ \\
\hline & PD & & CHI3L1 $\uparrow \rightarrow$ cognitive function $\downarrow^{226}$ \\
\hline \multirow[t]{4}{*}{ Urinary } & Renal disease & Kidney injury & $\begin{array}{l}\text { CHI3L } 1 \uparrow \text { in pediatric severe malaria, }{ }^{229} \text { ischemic injury, }{ }^{17} \text { cardiac }^{22} \\
\text { surgery-associated, }{ }^{230} \text { adult critically ill, }{ }^{228} \text { hospitalized patients }\end{array}$ \\
\hline & & Hemodialysis $^{234}$ & $\mathrm{CHI} 3 \mathrm{~L} 1 \uparrow \rightarrow$ mortality risk $\uparrow$ \\
\hline & & Nephrotic syndrome ${ }^{235}$ & CHI3L1 $\uparrow \rightarrow$ endothelial dysfunction and increased arterial stiffness \\
\hline & Bladder & $\begin{array}{l}\text { Bladder pain syndrome, interstitial } \\
\text { cystitis s } s^{233}\end{array}$ & $\mathrm{CHI} 3 \mathrm{~L} 1 \uparrow$ \\
\hline Skeletal & Joint & Arthritis & $\mathrm{CHI} 3 \mathrm{~L} 1 \uparrow^{236}$ \\
\hline
\end{tabular}

inflammatory airway disease. Moreover, high levels of serum $\mathrm{CHI} 3 \mathrm{~L} 1$ predicts disease progression and are associated with mortality of hypersensitivity pneumonitis. ${ }^{156}$ Furthermore, $\mathrm{CHI} 3 \mathrm{~L} 1$ has been regarded as a promising biomarker for evaluating severity of interstitial lung disease and predicting disease prognosis. $^{157,158}$

\section{Asthma}

CHI3L1 has been found in increased quantities in the serum and lungs in patients with asthma. ${ }^{159-161}$ Moreover, a promoter SNP $(-131 \mathrm{C} \rightarrow \mathrm{G})$ in $\mathrm{CHI} 3 \mathrm{~L} 1$ is associated with elevated serum CHI3L1 levels, asthma, bronchial hyper responsiveness, and measures of pulmonary function. ${ }^{162}$ Interestingly, CHI3L1 is induced by a high fat diet and contributes to the genesis of obesity and asthma. ${ }^{74}$ Mechanistically, CHI3L1 promotes bronchial smooth muscle cell proliferation and migration through a PAR-2-dependent mechanism. ${ }^{33}$

\section{Lung injury and fibrosis}

CHI3L1 has been reported to ameliorate hyperoxic acute lung injury and prolong mouse survival in $100 \% \mathrm{O}_{2}{ }^{30,68}$ In mammalian lung fibrosis $\mathrm{CHI}$ L1 1 plays a profibrotic role in the repair phase by augmenting alternative macrophage activation, fibroblast proliferation, and matrix deposition. ${ }^{163}$ Additionally, CHI3L1 exacerbates HPS-associated pulmonary fibrosis through binding to CRTH2 receptor. ${ }^{31,97}$ Serum CHI3L1 levels are also increased in patients with cystic fibrosis ${ }^{164}$ as well as asbestosis. ${ }^{165}$

Chronic obstructive pulmonary disease (COPD)

CHI3L1 is upregulated in COPD, ${ }^{166,167}$ in which it may contribute to tissue inflammation and remodeling by sustaining the synthesis of proinflammatory and fibrogenic chemokines and of metalloproteinases by alveolar macrophages. ${ }^{166}$

\section{CHI3L1 IN DIGESTIVE DISEASES}

Liver injury

There are different types of liver injury. In concanavalin A-induced liver damage, $\mathrm{CHI} 3 \mathrm{~L} 1$ promotes intrahepatic activation of coagulation and tissue injury through induction of tissue factor via MAPK activation. ${ }^{168}$ In acetaminophen-induced liver damage, CHI3L1 deficiency results in more severe liver injury. ${ }^{169}$ Moreover, the lack of CHI3L1 attenuates ethanol-induced liver injury by inhibition of sterol regulatory element-binding protein 1-dependent triglyceride synthesis. ${ }^{170}$ Additionally, ischemia-reperfusion injury in steatotic livers following transplantation are associated with MMP activation and $\mathrm{CHI} 3 \mathrm{~L} 1$ upregulation resulting in pro-fibrotic and proinflammatory cytokine release. ${ }^{171}$

Liver fibrosis

Chronic infection with hepatitis virus predisposes to liver fibrosis and end-stage liver complications. For HCV infection, it has been reported that the progression of fibrosis rate/year has a direct linear correlation for $\mathrm{CHI} 3 \mathrm{~L} 1$ which also shows a linear correlation with TGF- $\beta$ in patients with concomitant HCV and schistosomiasis infection. ${ }^{12}$ Moreover, elevated levels of serum CHI3L1 within the first 6 months after liver transplantation accurately predict rapid fibrosis progression. ${ }^{173} \mathrm{CHI}$ L1 1 remains associated with steatosis after controlling for fibrosis in Egyptian patients with HCV infection. ${ }^{174}$ Additionally, a functional upstream promoter polymorphism of CHI3L1 (rs4950928) in a large cohort of German patients with chronic HCV is associated with a lower stage of liver fibrosis as well as lower serum CHI3L1 levels. ${ }^{38}$ However, this promoter polymorphism is not associated with disease progression in patients in the United States with advanced fibrosis due to chronic HCV. ${ }^{175}$ Although serum CHI3L1 level is correlated with the Ishak stages of fibrosis and predicts advanced fibrosis and cirrhosis, it shows the false-positive rates in discriminating three clinically relevant stages of fibrosis. ${ }^{176}$ For hepatitis B virus (HBV) infection, serum ChI3L1 level is a feasible biomarker to identify advanced liver fibrosis in patients with HBV-related liver fibrosis. ${ }^{177-179}$ Moreover, CHI3L1 is regarded as a potential useful marker for monitoring the change of liver fibrosis in patients with chronic HBV infection during therapy. ${ }^{180}$ For alcohol-induced fibrosis, increased serum CHI3L1 in patients with liver disease of various degree and etiology seems to reflect fibrosis and fibrogenesis. ${ }^{181,182}$ Furthermore, in non-alcoholic fatty liver disease macrophage-derived $\mathrm{CHI} 3 \mathrm{~L} 1$ is also judged as a feasible biomarker of liver fibrosis in patients. ${ }^{183}$

Bowel disease

For inflammatory bowel disease (IBD), fecal CHI3L1 has been reported as a novel biomarker of disease activity in pediatric patients ${ }^{184}$ and endoscopic activity in adult patients. ${ }^{185}$ For colitis CHI3L1 exacerbates intestinal inflammation by binding to bacterial chitin-binding protein, ${ }^{186,187}$ enhancing bacterial adhesion and invasion, ${ }^{60}$ activating Akt signaling ${ }^{145}$ and IL-6-mediated STAT3 phosphorylation. $^{188}$ 


\section{CHI3L1 IN CARDIOVASCULAR DISEASES}

Atherosclerosis, coronary artery disease, peripheral artery disease, and giant cell arteritis

Plasma CHI3L1 levels correlate with the severity of coronary ${ }^{189,190}$ and carotid ${ }^{191}$ atherosclerosis. Moreover, atherosclerosis is exacerbated by $\mathrm{CHI} 3 \mathrm{~L} 1$ in amyloid precursor protein transgenic mice. ${ }^{192}$ Accordingly, CHI3L1 gene silencing could downregulate the expression of local proinflammatory mediators and inhibit plaques progression. ${ }^{193}$ Additionally, CHI3L1 is an early inflammatory marker in diabetic subjects even in the presence of a low atherosclerotic background, ${ }^{194,195}$ and is elevated in patients with peripheral arterial disease and diabetes or pre-diabetes. ${ }^{196,197}$ It has been revealed that CHI3L1 levels increase with declining ankle-brachial index and are associated with long-term cardiovascular mortality in peripheral arterial disease patients. ${ }^{198}$ For giant cell arteritis, CHI3L1 is found in $\mathrm{CD}^{+} 8^{+}$giant cells and mononuclear cells in the media of arteritic vessels of patients, and serum CHI3L1 level reflects the local activity of these cells in the inflamed artery. ${ }^{199}$

Thromboembolism, hypertension, atrial fibrillation, $\beta$-thalassemia major, and chronic heart failure

It has been reported that baseline plasma CHI3L1 level is significantly associated with incident thromboembolic stroke with a magnitude of effect. ${ }^{200}$ Similarly, high CHI3L1 levels are associated with a 2-fold increased risk of venous thromboembolism. ${ }^{201}$ Additionally, CHI3L1 is associated with hypertension incidence only among men in China. Moreover, in pulmonary arterial hypertension plasma CHI3L1 levels are significantly increased and regarded as a prognostic indicator. ${ }^{202}$ Furthermore, CHI3L1 has a potential for being a biomarker for endothelial dysfunction and hypertension in obstructive sleep apnea. ${ }^{203}$ For atrial fibrillation, elevated plasma $\mathrm{CHI} 3 \mathrm{~L} 1$ levels are robustly associated with its increased risk originating from hospital admissions or visits to the emergency department. ${ }^{204}$ Interestingly, CHI3L1 is highly expressed in the epicardial adipose tissue of patients with atrial fibrillation and associated with atrial fibrosis. ${ }^{205}$ Even in $\beta$-thalassemia major patients $\mathrm{CHI} 3 \mathrm{~L} 1$ is shown as a promising marker of cardiovascular disease and liver siderosis. ${ }^{206}$ In patients with chronic heart failure, high level of serum CHI3L1 is associated with higher rates of cardiac events and regarded as an independent prognostic factor. ${ }^{207}$

\section{CHI3L1 IN ENDOCRINE DISEASES}

Obesity, insulin resistance and diabetes

Low-grade chronic inflammation is associated with obesity and type 2 diabetes. CHI3L1 functions as an inflammatory regulator with relation to acute and chronic inflammation, and has played an important role in diabetes. CHI3L1 levels are elevated in morbidly obese patients ${ }^{208}$ and patients with type 2 diabetes, ${ }^{209,210}$ is related to insulin resistance, ${ }^{209}$ is independently associated with albuminuria, ${ }^{211,212}$ and is a BMl-independent marker. $^{213}$ Moreover, high CHI3L1 levels predict mortality in patients with type 2 diabetes. ${ }^{214}$ CHI3L1 is also elevated in patients with type 1 diabetes and increases with levels of albuminuria. $^{215}$

\section{CHI3L1 IN NERVOUS DISEASES}

Alzheimer's disease (AD) and Parkinson's disease (PD)

CHI3L1 is firstly identified as a potential candidate cerebrospinal fluid (CSF) biomarker for AD by using two-dimensional difference gel electrophoresis and liquid chromatography tandem mass spectrometry. ${ }^{216}$ The diagnostic function of $\mathrm{CHI} 3 \mathrm{~L} 1$ in $A D$ and other neurodegenerative diseases has been comprehensively summarized by Harald Hampel and his colleagues. ${ }^{217}$ Plasma CHI3L1 levels are not elevated in moderate/severe AD, suggesting

that plasma CHI3L1 increase probably occurred in early $A D$ phases. ${ }^{218}$ There is growing evidence suggesting that CSF CHI3L1 might be of diagnostic value in distinguishing $A D$ from healthy controls. However, some studies reported higher CSF CHI3L1 concentrations in $A D$ versus controls, ${ }^{219-222}$ while no significant differences were reported in other independent analyses. ${ }^{223,224} \mathrm{~A}$ meta-analysis compared CSF CHI3L1 in six different cohorts of $A D$ patients and five cohorts of normal controls demonstrating a moderate significant effect size. ${ }^{217,225}$ For PD, a significant increase of CSF CHI3L1 concentrations was observed in PD patients, after a 2-year follow-up, compared with baseline but not in healthy controls, and was associated to a faster cognitive decline in PD versus healthy controls. 226

\section{CHI3L1 IN URINARY DISEASES}

CHI3L1 has been identified as a critical mediator that limits tubular cell apoptotic death and improves animal survival after kidney ischemia/reperfusion by urine proteomic screen, thereby serving as a sensor of the degree of injury and a possible biomarker to identify patients at greatest risk of sustained renal failure after transplantation. ${ }^{17}$ Urine CHI3L1 is also associated with acute kidney injury (AKI) progression and/or death in hospitalized patients and improves clinically determined risk reclassification. ${ }^{227}$ Moreover, urine $\mathrm{CHI} 3 \mathrm{~L} 1$ is regarded as a biomarker for prediction of AKI stage $\geq 2$ in adult ICU patients. ${ }^{228}$ Especially, CHI3L1 is thought as a novel biomarker of malaria-associated AKI and an independent risk factor for mortality that is associated with wellestablished pathways of severe malaria pathogenesis including inflammation, endothelial activation, and hemolysis. ${ }^{229} \mathrm{~A}$ singlecenter prospective cohort study indicates that serum CHI3L1 combined with urine $\mathrm{CHI} 3 \mathrm{~L} 1$ is a good predictor of AKI associated with elective cardiac surgery at stage $\geq 2$ within $12 \mathrm{~h}$ after the time of post-operative ICU admission. ${ }^{230}$ In chronic kidney disease, urinary $\mathrm{CHI} 3 \mathrm{~L} 1$ is associated with higher risk of the kidney composite outcome in fully adjusted models including baseline eGFR and urine albumin. ${ }^{231} \mathrm{CHI} 3 \mathrm{~L} 1$ has been reported to promote renal fibrosis after kidney injury via activation of myofibroblasts. ${ }^{232}$ In bladder pain syndrome/interstitial cystitis serum and urine levels of CHI3L1 are suggested as non-invasive biomarkers for the evaluation of bladder fibrogenesis. ${ }^{233}$ In hemodialysis patients CHI3L1 significantly improves risk prediction for all-cause and cardiovascular mortality. ${ }^{234}$ In nephrotic syndrome patients the serum CHI3L1 level is associated with endothelial dysfunction and increased arterial stiffness and may be an indicator of the level of proteinuria in this patient population. ${ }^{235}$

\section{CHI3L1 IN SKELETAL DISEASES}

$\mathrm{OA}$ and rheumatoid arthritis

CHI3L1 is expressed in diseased human osteoarthritic cartilage and osteophyte, ${ }^{39}$ and is found to induce arthritis accompanied by pathologic changes in bone and cartilage. ${ }^{236}$ There are many studies indicating $\mathrm{CHI} 3 \mathrm{~L} 1$ as a cartilage-derived factor associated with mediators of inflammation and cartilage destruction involved in the pathogenesis of OA. ${ }^{237-240}$ For rheumatoid arthritis (RA), serum CHI3L1 in the RA patient group is significantly higher than that in the other patient groups and healthy controls, 241,242 is increased in $54 \%$ of the patients with clinically active disease, ${ }^{243}$ and elevated serum $\mathrm{CHI}$ L1 is related to progression in joint destruction in early RA patients. ${ }^{24,245}$ CHI3L1 in synovial fluid influences serum CHI3L1. Both are involved in the pathophysiology of the arthritic processes and reflect local disease activity. ${ }^{246}$ Moreover, $\mathrm{CHI} 3 \mathrm{~L} 1$ has been identified as a candidate autoantigen presented by HLA-DR in RA. ${ }^{247-250}$ Some patients with RA and OA possessed autoantibodies to CHI3L1. ${ }^{251,252}$ However, autoimmunity to CHI3L1 in patients with OA was present at equal or somewhat higher frequency than in patients with RA. The cellular 
and humoral immune responses to $\mathrm{CHI} 3 \mathrm{~L} 1$ may be involved in the pathological process of OA as well as RA. ${ }^{252}$

\section{TARGETING CHI3L1 FOR THERAPY}

Tumor

Owing to its overexpression in a wide array of cancer types, $\mathrm{CHI}$ L1 is now being regarded as a potential diagnostic marker and therapeutic target in oncology. ${ }^{253,254}$ For example, CHI3L1 is overexpressed in glioblastoma patients with poor survival. Encouragingly, a CHI3L1-neutralizing antibody effectively inhibits tube formation of microvascular endothelial cells, abolishes the CHI3L1-induced VEGF receptor 2 expression, and accelerates the apoptosis of glioblastoma U87 cells induced by $\gamma$-irradiation exposure through the blockade of Akt pathway. ${ }^{255}$ Glioblastoma U87 cells produce increased amounts of CHI3L1 during $Y^{-}$ irradiation-induced cell death, however, the blockade of CHI3L1 activity using a monoclonal neutralizing antibody decreased tumor growth, angiogenesis, and metastasis in a xenograft model. ${ }^{102}$ Consequently, a combination of CHI3L1-neutralizing antibody and ionizing irradiation synergistically inhibited tumor growth and increased mouse survival relative to single treatment in xenografted brain tumor mouse models. ${ }^{131}$ In temozolomideresistant (TMZ-R) glioblastoma, CHI3L1 inhibition suppressed invasive activity and partially restored the sensitivity to TMZ. ${ }^{63}$ The blockade of STAT3 by STX-0119 resulted in decreased CHI3L1 expression and inhibition of TMZ-R U87 cell growth. ${ }^{256}$ Targeting the CHI3L1-STAT3-mTOR signaling pathway using a combination of the mTOR inhibitor rapamycin and a STAT3 inhibitor produced a significant growth-inhibitory effect in TMZ-R relapsed gliomas. $^{257}$ In colon cancer, the migration of SW480 cells was significantly enhanced in the presence of CHI3L1, but was markedly inhibited by anti-CHI3L1 antibody treatment. ${ }^{118}$ Similarly, the addition of anti-CHI3L1 antibody in culture resulted in a significant decrease in the adhesion, migration, and invasion of GC (MKN-45) and breast cancer (MDA-MB-231) cells. ${ }^{150}$ In particular, a neutralizing anti-CHI3L1 antibody targeting the KR-rich domain (residues 334-345) abrogated angiogenesis and tumor cell migration in breast cancer. ${ }^{100}$

In addition to anti-CHI3L1-specific antibody and targeted chemical inhibitors, pan-family 18 chitinase inhibitors like chitin display identical blocking effect induced by CHI3L1. In mammary tumor-bearing mouse model, chitin treatment reduced the induction of proinflammatory mediators (CCL2, CXCL2, and MMP-9), tumor growth, and pulmonary metastasis induced by CHI3L1 overexpression. ${ }^{28}$ Moreover, resveratrol, a natural phenol, decreased the activity of the CHI3L1 promoter, reducing both mRNA transcription and protein expression, thereby repressing the growth, proliferation, and invasion of U87 MG cells in vitro. ${ }^{258}$

\section{Non-cancerous diseases}

It is now well-established that CHI3L1 plays a crucial role in the pathogenesis of many types of non-cancerous diseases. Therefore, $\mathrm{CHI} 3 \mathrm{~L} 1$ could serve as a potential therapeutic target. For instance, CHI3L1 is required for severe lung immunopathology caused by RSV infection. Consequently, in vivo neutralization of CHI3L1 using an anti-CHI3L1 antibody decreased the severity of IL-13-dominant airway inflammation during RSV infection. ${ }^{154}$ In IBD CHI3L1 enhances bacterial adhesion and invasion on/into CECs. Accordingly, inhibition of CHI3L1 by anti-CHI3L1 antibody or CHI3L1specific short interfering RNA reduces the adhesion of chitinbinding protein overexpressing $E$. coli to CECs. ${ }^{226}$ In RA CHI3L1 is identified as a HLA-DR-restricted autoantigen. The antibodies against CHI3L1 (263-275) peptide are able to inhibit (up to 90\%) the response of the peptide-specific HLA-DR-restricted $T$ cell hybridomas to peptide-pulsed APC or purified complexes. ${ }^{259}$ Moreover, inhalation of $\mathrm{CHI} 3 \mathrm{~L} 1$ protein leads to tolerization of antigen-specific $\mathrm{T}$ cells and to suppression of CHI3L1-induced arthritis in mice. ${ }^{247}$ Subsequently, the safety and tolerability and pilot efficacy of repeated single doses of Org39141 (recombinant human $\mathrm{CHI}$ L1) by intranasal administration was performed by a phase I escalating cohort study in patients with RA. ${ }^{260}$ As a consequence, Org 39141 is well tolerated, and no severe or serious adverse events is reported. After 4 weeks of treatment, the mean decrease in Org 39141 treatment group $(-24 \%)$ is statistically $(p=0.02)$ and clinically significantly larger than in the pooled placebo group $(-3 \%){ }^{260}$

In summary, considering the multiple roles of $\mathrm{CHILL}_{1}$ in oncogenesis, the direct neutralization of $\mathrm{CHI} 3 \mathrm{~L} 1$ will reduce tumor-associated inflammatory response, ECM degradation, angiogenesis, and tumor metastasis, thereby inhibiting tumor progression. ${ }^{150,261}$ Moreover, considering the binding partners involved in $\mathrm{CHI} 3 \mathrm{~L} 1$ signaling, reagents targeting and disrupting these interactions warrant further investigation in future cancer research and clinical trials. Likewise, considering the effects of CHI3L1 in pathogenesis of non-cancerous diseases, the techniques blocking the function of CHI3L1 including neutralizing antibodies, small interfering RNA and microRNA can be introduced to ameliorate the disease symptoms. Since $\mathrm{CHI} 3 \mathrm{~L} 1$ has been revealed as an autoantigen in RA, the recombinant protein can be employed to induce mucosal tolerance by intranasal administration for further clinical development.

\section{CLOSING THOUGHTS}

Much has been known about the effect of CHI3L1 in disease pathologies in the past 30 years. It is perhaps tempting to ponder how we might integrate this knowledge into clinical applications. However, some puzzles still need to be solved.

First, what are all functional domains or structures in $\mathrm{CHI}$ L1 molecule? CHI3L1 has a triose-phosphate isomerase barrel-like structure with the insertion of beta-strands domain, and binds chitin and chito-oligosaccharides using nine GlcNAc-binding subsites. A chemical candidate was identified as a CHI3L1 inhibitor to attenuate NF-KB activation and NF-KB-related neuroinflammatory gene expression, ${ }^{65}$ and the binding sites were further analyzed by a docking model. ${ }^{262}$ It was found that the antibody against CHI3L1 (325-339) peptide reduced the adhesion of chitin-binding protein-overexpressing E. coli to CECs, ${ }^{186}$ thereby revealing the importance of the region (325-339) in the $\mathrm{CHI} 3 \mathrm{~L} 1$ structure. Once the functional domains or structures are fully identified, the chemicals or antibodies will be able to be designed or produced to target them precisely.

Second, whether is the function of CHI3L1 redundant? CHI3L2 is a protein of unknown function closely related to $\mathrm{CHI}$ L1 sharing $51 \%$ identities and $71 \%$ positives and present in humans and other primates. $\mathrm{CHI} 3 \mathrm{~L} 3(\mathrm{Ym} 1)$ and $\mathrm{CHI} 3 \mathrm{~L} 4(\mathrm{Ym} 2)$ are proteins with unknown function closely related to $\mathrm{CHI} 3 \mathrm{~L} 1$ in mice, sharing $43 \%$ identities and $61 \%$ positives, $42 \%$ identities and $59 \%$ positives to $\mathrm{CHI} 3 \mathrm{~L} 1$, respectively. Once the functional redundancy of all proteins is determined, the targets may be expanded accordingly to eliminate all effects.

Third, are there any as-yet unknown receptors or ligands of CHI3L1? Although a few receptors have been identified, there still might be novel ones. Especially, some membrane proteins with functional intracellular domains may function as $\mathrm{CHI} 3 \mathrm{~L} 1$ receptors. Probably, the protein complexes need to be formed and function in CHI3L1 signaling.

Forth, how does CHI3L1 signaling influence neutrophils, monocytes, or macrophages recruitment? CHI3L1 participates in the infiltration of neutrophils in lung ${ }^{69}$ and in liver (our unpublished data). Although some kinases have been reported to be activated and involved, the direct functional receptors remain to be further investigated.

Fifth, what is the exact function of $\mathrm{CHI} 3 \mathrm{~L} 1$ in liver fibrosis? The cellular sources of $\mathrm{CHI} 3 \mathrm{~L} 1$ in liver include hepatocytes, neutrophils, 


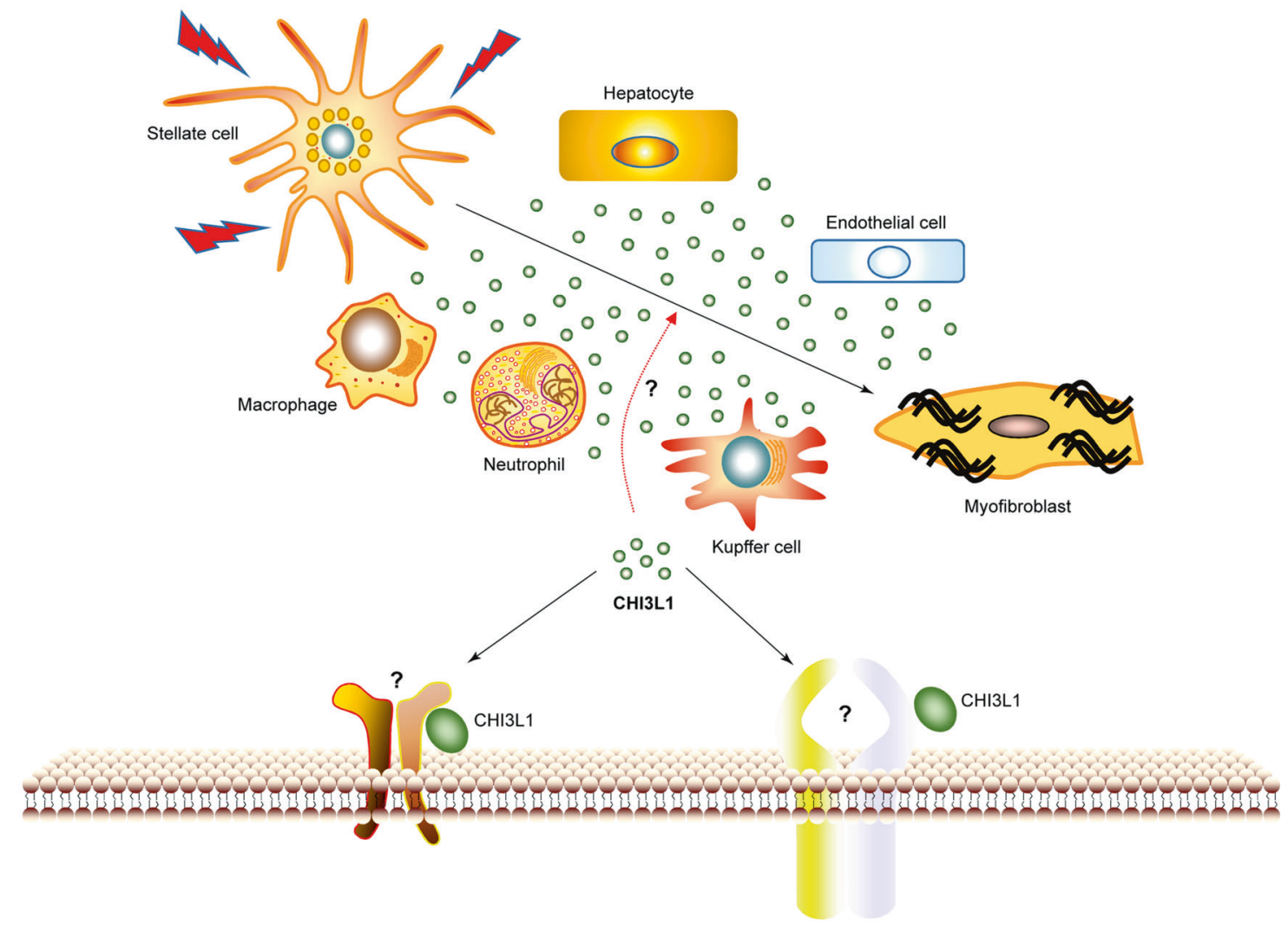

Fig. 7 Possible effects of CHI3L1 on liver fibrosis

macrophages, and endothelial cells (Fig. 7). Numerous studies show that CHI3L1 upregulates in liver fibrosis caused by virus infection, alcohol, or the accumulation of liver lipid. A recent paper shows that $\mathrm{CHI} 3 \mathrm{~L} 1$ deficiency ameliorates liver fibrosis by promoting hepatic macrophage apoptosis. ${ }^{262}$ However, the exact effect or the involved receptors still remain to be determined. The success of CHI3L1-targeted therapies will depend on whether we can differentiate CHI3L1 functions and its receptors in various biological and pathological responses.

\section{ACKNOWLEDGEMENTS}

This study was supported by Guangzhou key medical discipline construction project and the National Natural Science Foundation of China (grant numbers 81671543, 81870409 to Q.Y.).

\section{AUTHOR CONTRIBUTIONS}

Q.Y. and X.Z provided direction and guidance throughout the preparation of this manuscript. T.Z., Z.S., and Y.L. collected and prepared the related literature. T.Z. drafted the manuscript. All authors have read and approved the final manuscript.

\section{ADDITIONAL INFORMATION}

Competing interests: The authors declare no competing interests.

\section{REFERENCES}

1. Johansen, J. S., Williamson, M. K., Rice, J. S. \& Price, P. A. Identification of proteins secreted by human osteoblastic cells in culture. J. Bone Miner. Res. 7, 501-512 (1992).

2. Hakala, B. E., White, C. \& Recklies, A. D. Human cartilage gp-39, a major secretory product of articular chondrocytes and synovial cells, is a mammalian member of a chitinase protein family. J. Biol. Chem. 268, 25803-25810 (1993).

3. Shackelton, L. M., Mann, D. M. \& Millis, A. J. Identification of a 38-kDa heparinbinding glycoprotein (gp38k) in differentiating vascular smooth muscle cells as a member of a group of proteins associated with tissue remodeling. J. Biol. Chem. 270, 13076-13083 (1995).

4. Junker, N., Johansen, J. S., Andersen, C. B. \& Kristjansen, P. E. Expression of YKL40 by peritumoral macrophages in human small cell lung cancer. Lung Cancer 48, 223-231 (2005)

5. Recklies, A. D., White, C. \& Ling, H. The chitinase 3-like protein human cartilage glycoprotein 39 (HC-gp39) stimulates proliferation of human connective-tissue cells and activates both extracellular signal-regulated kinaseand protein kinase B-mediated signalling pathways. Biochem. J. 365, 119-126 (2002).

6. Junker, N., Johansen, J. S., Hansen, L. T., Lund, E. L. \& Kristjansen, P. E. Regulation of YKL-40 expression during genotoxic or microenvironmental stress in human glioblastoma cells. Cancer Sci. 96, 183-190 (2005).

7. Bonneh-Barkay, D. et al. YKL-40, a marker of simian immunodeficiency virus encephalitis, modulates the biological activity of basic fibroblast growth factor. Am. J. Pathol. 173, 130-143 (2008).

8. Renkema, G. H. et al. Chitotriosidase, a chitinase, and the 39-kDa human cartilage glycoprotein, a chitin-binding lectin, are homologues of family 18 glycosyl hydrolases secreted by human macrophages. Eur. J. Biochem. 251, 504-509 (1998).

9. Gorgens, S. W., Eckardt, K., Elsen, M., Tennagels, N. \& Eckel, J. Chitinase-3-like protein 1 protects skeletal muscle from TNFalpha-induced inflammation and insulin resistance. Biochem. J. 459, 479-488 (2014).

10. Millis, A. J., Hoyle, M., Reich, E. \& Mann, D. M. Isolation and characterization of a $\mathrm{Mr}=38,000$ protein from differentiating smooth muscle cells. J. Biol. Chem. 260, 3754-3761 (1985).

11. Johansen, J. S. et al. Regulation of YKL-40 production by human articular chondrocytes. Arthritis Rheum. 44, 826-837 (2001).

12. De Ceuninck, F., Pastoureau, P., Bouet, F., Bonnet, J. \& Vanhoutte, P. M. Purification of guinea pig YKL40 and modulation of its secretion by cultured articular chondrocytes. J. Cell. Biochem. 69, 414-424 (1998).

13. Kzhyshkowska, J. et al. Novel stabilin-1 interacting chitinase-like protein (SI-CLP) is up-regulated in alternatively activated macrophages and secreted via lysosomal pathway. Blood 107, 3221-3228 (2006).

14. Fusetti, F., Pijning, T., Kalk, K. H., Bos, E. \& Dijkstra, B. W. Crystal structure and carbohydrate-binding properties of the human cartilage glycoprotein-39. J. Biol. Chem. 278, 37753-37760 (2003). 
15. Houston, D. R., Recklies, A. D., Krupa, J. C. \& van Aalten, D. M. Structure and ligand-induced conformational change of the 39-kDa glycoprotein from human articular chondrocytes. J. Biol. Chem. 278, 30206-30212 (2003).

16. Dela Cruz, C. S. et al. Chitinase 3-like-1 promotes Streptococcus pneumoniae killing and augments host tolerance to lung antibacterial responses. Cell Host Microbe 12, 34-46 (2012).

17. Schmidt, I. M. et al. Chitinase-like protein Brp-39/YKL-40 modulates the renal response to ischemic injury and predicts delayed allograft function. J. Am. Soc. Nephrol. 24, 309-319 (2013).

18. He, C. H. et al. Chitinase 3 -like 1 regulates cellular and tissue responses via IL-13 receptor alpha2. Cell Rep. 4, 830-841 (2013).

19. $\mathrm{Xu}, \mathrm{N}$. et al. Chitinase-3-Like-1 promotes $M 2$ macrophage differentiation and induces choroidal neovascularization in neovascular age-related macular degeneration. Invest. Ophthalmol. Vis. Sci. 60, 4596-4605 (2019).

20. Bergmann, O. J. et al. High serum concentration of YKL-40 is associated with short survival in patients with acute myeloid leukemia. Clin. Cancer Res. 11, 8644-8652 (2005).

21. Cintin, $C$. et al. High serum YKL-40 level after surgery for colorectal carcinoma is related to short survival. Cancer 95, 267-274 (2002).

22. Brasso, K. et al. Prognostic value of PINP, bone alkaline phosphatase, CTX-I, and YKL-40 in patients with metastatic prostate carcinoma. Prostate 66, 503-513 (2006).

23. Jensen, B. V., Johansen, J. S. \& Price, P. A. High levels of serum HER-2/neu and YKL-40 independently reflect aggressiveness of metastatic breast cancer. Clin. Cancer Res. 9, 4423-4434 (2003).

24. Johansen, J. S., Drivsholm, L., Price, P. A. \& Christensen, I. J. High serum YKL-40 level in patients with small cell lung cancer is related to early death. Lung Cancer 46, 333-340 (2004).

25. Pelloski, C. E. et al. YKL-40 expression is associated with poorer response to radiation and shorter overall survival in glioblastoma. Clin. Cancer Res. 11, 3326-3334 (2005).

26. Hogdall, E. V. et al. High plasma YKL-40 level in patients with ovarian cancer stage III is related to shorter survival. Oncol. Rep. 10, 1535-1538 (2003).

27. Schmidt, $\mathrm{H}$. et al. Elevated serum level of $\mathrm{YKL}-40$ is an independent prognostic factor for poor survival in patients with metastatic melanoma. Cancer 106, 1130-1139 (2006).

28. Libreros, S. et al. Induction of proinflammatory mediators by $\mathrm{CHI} 3 \mathrm{~L} 1$ is reduced by chitin treatment: decreased tumor metastasis in a breast cancer model. Int. J. Cancer 131, 377-386 (2012).

29. Kawada, M. et al. Chitinase 3 -like 1 promotes macrophage recruitment and angiogenesis in colorectal cancer. Oncogene 31, 3111-3123 (2012).

30. Lee, C. M. et al. IL-13Ralpha2 uses TMEM219 in chitinase 3-like-1-induced signalling and effector responses. Nat. Commun. 7, 12752 (2016).

31. Zhou, Y. et al. Galectin-3 Interacts with the CHI3L1 axis and contributes to Hermansky-Pudlak syndrome lung disease. J. Immunol. 200, 2140-2153 (2018).

32. Geng, B. et al. Chitinase 3-like 1-CD44 interaction promotes metastasis and epithelial-to-mesenchymal transition through beta-catenin/Erk/Akt signaling in gastric cancer. J. Exp. Clin. Cancer Res. 37, 208 (2018).

33. Bara, I. et al. Role of YKL-40 in bronchial smooth muscle remodeling in asthma. Am. J. Respir. Crit. Care Med. 185, 715-722 (2012).

34. Shao, R. et al. YKL-40, a secreted glycoprotein, promotes tumor angiogenesis. Oncogene 28, 4456-4468 (2009).

35. Rehli, M., Krause, S. W. \& Andreesen, R. Molecular characterization of the gene for human cartilage gp-39 (CHI3L1), a member of the chitinase protein family and marker for late stages of macrophage differentiation. Genomics 43, 221-225 (1997).

36. Kjaergaard, A. D., Johansen, J. S., Nordestgaard, B. G. \& Bojesen, S. E. Genetic variants in CHI3L1 influencing YKL-40 levels: resequencing 900 individuals and genotyping 9000 individuals from the general population. J. Med. Genet. 50, 831-837 (2013)

37. Kruit, A., Grutters, J. C., Ruven, H. J., van Moorsel, C. C. \& van den Bosch, J. M. A CHI3L1 gene polymorphism is associated with serum levels of YKL-40, a novel sarcoidosis marker. Respir. Med. 101, 1563-1571 (2007).

38. Berres, M. L. et al. A functional variation in CHI3L1 is associated with severity of liver fibrosis and YKL-40 serum levels in chronic hepatitis $C$ infection. J. Hepatol. 50, 370-376 (2009).

39. Gomez, J. L. et al. Genetic variation in chitinase 3-like 1 (CHI3L1) contributes to asthma severity and airway expression of YKL-40. J. Allergy Clin. Immunol. 136, 51-58 e10 (2015)

40. Chen, G. et al. Functional study of the association of CHI3L1 polymorphisms with asthma susceptibility in the Southwest Chinese Han population. Biosci. Rep. 39, BSR20182008 (2019).

41. $\mathrm{Ku}, \mathrm{B} . \mathrm{M}$. et al. CHI3L1 (YKL-40) is expressed in human gliomas and regulates the invasion, growth and survival of glioma cells. Int. J. Cancer 128, 1316-1326 (2011).
42. Kazakova, M. H. \& Sarafian, V. S. YKL-40-a novel biomarker in clinical practice? Folia Med. 51, 5-14 (2009).

43. Fusetti, F., Pijning, T., Kalk, K. H., Bos, E. \& Dijkstra, B. W. Crystal structure and carbohydrate-binding properties of the human cartilage glycoprotein-39. J. Biol. Chem. 278, 37753-37760 (2003).

44. Choudhuri, S. et al. A repertoire of biomarkers helps in detection and assessment of therapeutic response in epithelial ovarian cancer. Mol. Cell. Biochem. 386, 259-269 (2014).

45. Schultz, N. A. \& Johansen, J. S. YKL-40-A protein in the field of translational medicine: a role as a biomarker in cancer patients? Cancers 2, 1453-1491 (2010).

46. Kronborg, G. et al. Serum level of YKL-40 is elevated in patients with Streptococcus pneumoniae bacteremia and is associated with the outcome of the disease. Scand. J. Infect. Dis. 34, 323-326 (2002).

47. Connor, J. R. et al. Human cartilage glycoprotein 39 (HC gp-39) mRNA expression in adult and fetal chondrocytes, osteoblasts and osteocytes by in-situ hybridization. Osteoarthr. Cartil. 8, 87-95 (2000).

48. Rejman, J. J. \& Hurley, W. L. Isolation and characterization of a novel 39 kilodalton whey protein from bovine mammary secretions collected during the nonlactating period. Biochem. Biophys. Res. Commun. 150, 329-334 (1988).

49. Furuhashi, K. et al. Increased expression of YKL-40, a chitinase-like protein, in serum and lung of patients with idiopathic pulmonary fibrosis. Respir. Med. 104, 1204-1210 (2010).

50. Harvey, S. et al. Chondrex: new marker of joint disease. Clin. Chem. 44, 509-516 (1998).

51. Zheng, J. L. et al. Increased serum YKL-40 and C-reactive protein levels are associated with angiographic lesion progression in patients with coronary artery disease. Atherosclerosis 210, 590-595 (2010).

52. Hattori, N. et al. YKL-40 identified by proteomic analysis as a biomarker of sepsis. Shock 32, 393-400 (2009).

53. Rathcke, C. N. \& Vestergaard, H. YKL-40-an emerging biomarker in cardiovascular disease and diabetes. Cardiovasc. Diabetol. 8, 61 (2009).

54. Seol, H. J. et al. Serum levels of YKL-40 and interleukin-18 and their relationship to disease severity in patients with preeclampsia. J. Reprod. Immunol. 79, 183-187 (2009).

55. Deng, $X$. et al. Circulating miRNA-24 and its target YKL-40 as potential biomarkers in patients with coronary heart disease and type 2 diabetes mellitus. Oncotarget 8, 63038-63046 (2017).

56. Jin, T. et al. The role of MicroRNA, miR-24, and its target CHI3L1 in osteomyelitis caused by Staphylococcus aureus. J. Cell. Biochem. 116, 2804-2813 (2015).

57. Maegdefessel, L. et al. miR-24 limits aortic vascular inflammation and murine abdominal aneurysm development. Nat. Commun. 5, 5214 (2014).

58. Sarma, N. J. et al. Hepatitis $C$ virus mediated changes in miRNA-449a modulates inflammatory biomarker YKL40 through components of the NOTCH signaling pathway. PLoS ONE 7, e50826 (2012).

59. Choi, J. Y. et al. K284-6111 prevents the amyloid beta-induced neuroinflammation and impairment of recognition memory through inhibition of NFkappaB-mediated CHI3L1 expression. J. Neuroinflamm. 15, 224 (2018).

60. Mizoguchi, E. Chitinase 3-like-1 exacerbates intestinal inflammation by enhancing bacterial adhesion and invasion in colonic epithelial cells. Gastroenterology 130, 398-411 (2006).

61. De Ceuninck, F. et al. YKL-40 (cartilage gp-39) induces proliferative events in cultured chondrocytes and synoviocytes and increases glycosaminoglycan synthesis in chondrocytes. Biochem. Biophys. Res. Commun. 285, 926-931 (2001).

62. Zhang, W. et al. Association between YKL-40 and adult primary astrocytoma. Cancer 116, 2688-2697 (2010).

63. Akiyama, Y. et al. YKL-40 downregulation is a key factor to overcome temozolomide resistance in a glioblastoma cell line. Oncol. Rep. 32, 159-166 (2014).

64. Tang, $H$. et al. YKL-40 induces IL-8 expression from bronchial epithelium via MAPK (JNK and ERK) and NF-kappaB pathways, causing bronchial smooth muscle proliferation and migration. J. Immunol. 190, 438-446 (2013).

65. Kamba, A., Lee, I. A. \& Mizoguchi, E. Potential association between TLR4 and chitinase 3-like 1 (CHI3L1/YKL-40) signaling on colonic epithelial cells in inflammatory bowel disease and colitis-associated cancer. Curr. Mol. Med. 13, 1110-1121 (2013)

66. Malinda, K. M., Ponce, L., Kleinman, H. K., Shackelton, L. M. \& Millis, A. J. Gp38k, a protein synthesized by vascular smooth muscle cells, stimulates directional migration of human umbilical vein endothelial cells. Exp. Cell Res. 250, 168-173 (1999).

67. Harutyunyan, M. et al. The inflammatory biomarker YKL-40 as a new prognostic marker for all-cause mortality in patients with heart failure. Immunobiology 217, 652-656 (2012).

68. Lee, C. G. et al. Role of chitin and chitinase/chitinase-like proteins in inflammation, tissue remodeling, and injury. Annu. Rev. Physiol. 73, 479-501 (2011). 
69. Lee, C. G. et al. Role of breast regression protein 39 (BRP-39)/chitinase 3-like-1 in Th2 and IL-13-induced tissue responses and apoptosis. J. Exp. Med. 206, 1149-1166 (2009).

70. Edwards, L. A. et al. Inhibition of ILK in PTEN-mutant human glioblastomas inhibits PKB/Akt activation, induces apoptosis, and delays tumor growth. Oncogene 24, 3596-3605 (2005).

71. Kavsan, V. M. et al. Gene encoding chitinase 3-like 1 protein (CHI3L1) is a putative oncogene. Int. J. Biomed. Sci. 7, 230-237 (2011).

72. Rehli, M. et al. Transcriptional regulation of $\mathrm{CHI} 3 \mathrm{~L} 1$, a marker gene for late stages of macrophage differentiation. J. Biol. Chem. 278, 44058-44067 (2003).

73. Kim, D. H. et al. Regulation of chitinase-3-like-1 in T cell elicits Th1 and cytotoxic responses to inhibit lung metastasis. Nat. Commun. 9, 503 (2018).

74. Ahangari, F. et al. Chitinase 3-like-1 regulates both visceral fat accumulation and asthma-like Th2 inflammation. Am. J. Respir. Crit. Care Med. 191, 746-757 (2015).

75. Di Rosa, M. et al. CHI3L1 nuclear localization in monocyte derived dendritic cells. Immunobiology 221, 347-356 (2016).

76. Michel, G., Tonon, T., Scornet, D., Cock, J. M. \& Kloareg, B. The cell wall polysaccharide metabolism of the brown alga Ectocarpus siliculosus. Insights into the evolution of extracellular matrix polysaccharides in Eukaryotes. New Phytol. 188, 82-97 (2010)

77. Discher, D. E., Janmey, P. \& Wang, Y. L. Tissue cells feel and respond to the stiffness of their substrate. Science 310, 1139-1143 (2005).

78. Engler, A. J., Sen, S., Sweeney, H. L. \& Discher, D. E. Matrix elasticity directs stem cell lineage specification. Cell 126, 677-689 (2006).

79. Liotta, L. A. Tumor invasion and metastases-role of the extracellular matrix: Rhoads Memorial Award lecture. Cancer Res. 46, 1-7 (1986).

80. Iwata, T. et al. YKL-40 secreted from adipose tissue inhibits degradation of type I collagen. Biochem. Biophys. Res. Commun. 388, 511-516 (2009).

81. Scully, S., Yan, W., Bentley, B., Cao, Q. J. \& Shao, R. Inhibitory activity of YKL-40 in mammary epithelial cell differentiation and polarization induced by lactogenic hormones: a role in mammary tissue involution. PLOS ONE 6, e25819 (2011).

82. Christofori, G. \& Semb, H. The role of the cell-adhesion molecule E-cadherin as a tumour-suppressor gene. Trends Biochem. Sci. 24, 73-76 (1999).

83. Ramos-DeSimone, N. et al. Activation of matrix metalloproteinase-9 (MMP-9) via a converging plasmin/stromelysin-1 cascade enhances tumor cell invasion. J. Biol. Chem. 274, 13066-13076 (1999).

84. Ling, H. \& Recklies, A. D. The chitinase 3-like protein human cartilage glycoprotein 39 inhibits cellular responses to the inflammatory cytokines interleukin1 and tumour necrosis factor-alpha. Biochem. J. 380, 651-659 (2004).

85. Hwang, H. S., Park, S. J., Cheon, E. J., Lee, M. H. \& Kim, H. A. Fibronectin fragmentinduced expression of matrix metalloproteinases is mediated by MyD88dependent TLR-2 signaling pathway in human chondrocytes. Arthritis Res. Ther. 17, 320 (2015).

86. Brooks, P. C. et al. Localization of matrix metalloproteinase MMP-2 to the surface of invasive cells by interaction with integrin alpha v beta 3. Cell 85, 683-693 (1996).

87. Hsi, L. C. et al. Silencing IL-13Ralpha2 promotes glioblastoma cell death via endogenous signaling. Mol. Cancer Ther. 10, 1149-1160 (2011).

88. Zhao, Z., Wang, L. \& Xu, W. IL-13Ralpha2 mediates PNR-induced migration and metastasis in ERalpha-negative breast cancer. Oncogene 34, 1596-1607 (2015).

89. Murata, T., Obiri, N. I. \& Puri, R. K. Human ovarian-carcinoma cell lines express IL4 and IL-13 receptors: comparison between IL-4- and IL-13-induced signal transduction. Int. J. Cancer 70, 230-240 (1997).

90. Barderas, R., Bartolome, R. A., Fernandez-Acenero, M. J., Torres, S. \& Casal, J. I. High expression of IL-13 receptor alpha2 in colorectal cancer is associated with invasion, liver metastasis, and poor prognosis. Cancer Res. 72, 2780-2790 (2012).

91. Brown, C. E. et al. Regression of glioblastoma after chimeric antigen receptor Tcell therapy. N. Engl. J. Med. 375, 2561-2569 (2016).

92. Donaldson, D. D. et al. The murine IL-13 receptor alpha 2: molecular cloning, characterization, and comparison with murine IL-13 receptor alpha 1. J. Immunol. 161, 2317-2324 (1998).

93. LaPorte, S. L. et al. Molecular and structural basis of cytokine receptor pleiotropy in the interleukin-4/13 system. Cell 132, 259-272 (2008).

94. He, C. H. et al. N-glycosylation regulates chitinase 3-like-1 and IL-13 ligand binding to IL-13 receptor alpha2. Am. J. Respir. Cell Mol. Biol. 63, 386-395 (2020).

95. Ingermann, A. R. et al. Identification of a novel cell death receptor mediating IGFBP-3-induced anti-tumor effects in breast and prostate cancer. J. Biol. Chem. 285, 30233-30246 (2010).

96. Mackinnon, A. C. et al. Regulation of transforming growth factor-beta1-driven lung fibrosis by galectin-3. Am. J. Respir. Crit. Care Med. 185, 537-546 (2012).

97. Zhou, Y. et al. Chitinase 3 -like-1 and its receptors in Hermansky-Pudlak syndrome-associated lung disease. J. Clin. Investig. 125, 3178-3192 (2015).

98. Ponta, H., Sherman, L. \& Herrlich, P. A. CD44: from adhesion molecules to signalling regulators. Nat. Rev. Mol. Cell Biol. 4, 33-45 (2003).
99. Nishikawa, K. C. \& Millis, A. J. gp38k (CHI3L1) is a novel adhesion and migration factor for vascular cells. Exp. Cell Res. 287, 79-87 (2003).

100. Ngernyuang, $\mathrm{N}$. et al. A heparin binding motif rich in arginine and lysine is the functional domain of YKL-40. Neoplasia 20, 182-192 (2018).

101. Hsueh, Y. P., Roberts, A. M., Volta, M., Sheng, M. \& Roberts, R. G. Bipartite interaction between neurofibromatosis type I protein (neurofibromin) and syndecan transmembrane heparan sulfate proteoglycans. J. Neurosci. 21, 3764-3770 (2001).

102. Francescone, R. A. et al. Role of YKL-40 in the angiogenesis, radioresistance, and progression of glioblastoma. J. Biol. Chem. 286, 15332-15343 (2011).

103. Tang, W. J., Fernandez, J., Sohn, J. J. \& Amemiya, C. T. Chitin is endogenously produced in vertebrates. Curr. Biol. 25, 897-900 (2015).

104. Debono, M. \& Gordee, R. S. Antibiotics that inhibit fungal cell wall development. Annu. Rev. Microbiol 48, 471-497 (1994).

105. Mohamadzadeh, M., DeGrendele, H., Arizpe, H., Estess, P. \& Siegelman, M. Proinflammatory stimuli regulate endothelial hyaluronan expression and CD44/ HA-dependent primary adhesion. J. Clin. Invest. 101, 97-108 (1998).

106. Shu, X. Z. et al. Attachment and spreading of fibroblasts on an RGD peptidemodified injectable hyaluronan hydrogel. J. Biomed. Mater. Res. A 68, 365-375 (2004).

107. Chen, W. Y. \& Abatangelo, G. Functions of hyaluronan in wound repair. Wound Repair Regen. 7, 79-89 (1999).

108. Bharadwaj, A. G. et al. Spontaneous metastasis of prostate cancer is promoted by excess hyaluronan synthesis and processing. Am. J. Pathol. 174, 1027-1036 (2009).

109. Zheng, M., Cai, W. M., Zhao, J. K., Zhu, S. M. \& Liu, R. H. Determination of serum levels of YKL-40 and hyaluronic acid in patients with hepatic fibrosis due to schistosomiasis japonica and appraisal of their clinical value. Acta Trop. 96, 148-152 (2005).

110. Bigg, H. F., Wait, R., Rowan, A. D. \& Cawston, T. E. The mammalian chitinase-like lectin, YKL-40, binds specifically to type I collagen and modulates the rate of type I collagen fibril formation. J. Biol. Chem. 281, 21082-21095 (2006).

111. Bhat, K. P. et al. Selective repression of YKL-40 by NF-kappaB in glioma cell lines involves recruitment of histone deacetylase-1 and -2. FEBS Lett. 582, 3193-3200 (2008).

112. Biggar, R. J. et al. Serum YKL-40 and interleukin 6 levels in Hodgkin lymphoma. Clin. Cancer Res. 14, 6974-6978 (2008).

113. Itik, V. et al. Serum YKL-40 levels in patients with gastric cancer. Biomark. Cancer 3, 25-30 (2011).

114. Cintin, C. et al. Serum YKL-40 and colorectal cancer. Br. J. Cancer 79, 1494-1499 (1999).

115. Dehn, H. et al. Plasma YKL-40, as a prognostic tumor marker in recurrent ovarian cancer. Acta Obstet. Gynecol. Scand. 82, 287-293 (2003).

116. Pelloski, C. E. et al. Prognostic associations of activated mitogen-activated protein kinase and Akt pathways in glioblastoma. Clin. Cancer Res. 12, 3935-3941 (2006).

117. Areshkov, P. O., Avdieiev, S. S., Balynska, O. V., Leroith, D. \& Kavsan, V. M. Two closely related human members of chitinase-like family, CHI3L1 and CHI3L2, activate ERK1/2 in 293 and U373 cells but have the different influence on cell proliferation. Int. J. Biol. Sci. 8, 39-48 (2012)

118. Chen, C. C. et al. Chitinase 3-like-1 expression in colonic epithelial cells as a potentially novel marker for colitis-associated neoplasia. Am. J. Pathol. 179, 1494-1503 (2011).

119. Libreros, S. et al. Allergen induced pulmonary inflammation enhances mammary tumor growth and metastasis: Role of CHI3L1. J. Leukoc. Biol. 97, 929-940 (2015).

120. Chaffer, C. L. \& Weinberg, R. A. A perspective on cancer cell metastasis. Science 331, 1559-1564 (2011).

121. Thom, I. et al. Elevated pretreatment serum concentration of YKL-40-An independent prognostic biomarker for poor survival in patients with metastatic nonsmall cell lung cancer. Cancer 116, 4114-4121 (2010).

122. Luo, D. et al. CHI3L1 overexpression is associated with metastasis and is an indicator of poor prognosis in papillary thyroid carcinoma. Cancer Biomark. 18, 273-284 (2017).

123. Lau, S. H. et al. Clusterin plays an important role in hepatocellular carcinoma metastasis. Oncogene 25, 1242-1250 (2006).

124. Jeet, V., Tevz, G., Lehman, M., Hollier, B. \& Nelson, C. Elevated YKL40 is associated with advanced prostate cancer ( $\mathrm{PCa}$ ) and positively regulates invasion and migration of PCa cells. Endocr. Relat. Cancer 21, 723-737 (2014).

125. Ngernyuang, $\mathrm{N}$. et al. Chitinase 3 like 1 is associated with tumor angiogenesis in cervical cancer. Int. J. Biochem. Cell Biol. 51, 45-52 (2014).

126. Mani, S. A. et al. The epithelial-mesenchymal transition generates cells with properties of stem cells. Cell 133, 704-715 (2008).

127. Jefri, M., Huang, Y. N., Huang, W. C., Tai, C. S. \& Chen, W. L. YKL-40 regulated epithelial-mesenchymal transition and migration/invasion enhancement in nonsmall cell lung cancer. BMC Cancer 15, 590 (2015). 
128. Hao, H. et al. YKL-40 promotes the migration and invasion of prostate cancer cells by regulating epithelial mesenchymal transition. Am. J. Transl. Res. 9 3749-3757 (2017)

129. Luca, M. et al. Expression of interleukin-8 by human melanoma cells upregulates MMP-2 activity and increases tumor growth and metastasis. Am. J. Pathol. 151, 1105-1113 (1997).

130. Holleb, A. I. \& Folkman, J. Tumor angiogenesis. CA Cancer J. Clin. 22, 226-229 (1972).

131. Shao, R. et al. Anti-YKL-40 antibody and ionizing irradiation synergistically inhibit tumor vascularization and malignancy in glioblastoma. Carcinogenesis 35, 373-382 (2014).

132. Shao, R. YKL-40 acts as an angiogenic factor to promote tumor angiogenesis. Front. Physiol. 4, 122 (2013).

133. Grunewald, F. S., Prota, A. E., Giese, A. \& Ballmer-Hofer, K. Structure-function analysis of VEGF receptor activation and the role of coreceptors in angiogenic signaling. Biochim. Biophys. Acta 1804, 567-580 (2010).

134. Libreros, S., Garcia-Areas, R., Keating, P., Carrio, R. \& Iragavarapu-Charyulu, V. L. Exploring the role of $\mathrm{CHI}$ L1 in "pre-metastatic" lungs of mammary tumorbearing mice. Front. Physiol. 4, 392 (2013).

135. Folberg, R., Hendrix, M. J. \& Maniotis, A. J. Vasculogenic mimicry and tumor angiogenesis. Am. J. Pathol. 156, 361-381 (2000).

136. Maniotis, A. J. et al. Vascular channel formation by human melanoma cells in vivo and in vitro: vasculogenic mimicry. Am. J. Pathol. 155, 739-752 (1999).

137. Williamson, S. C. et al. Vasculogenic mimicry in small cell lung cancer. Nat Commun. 7, 13322 (2016).

138. El Hallani, S. et al. A new alternative mechanism in glioblastoma vascularization: tubular vasculogenic mimicry. Brain 133, 973-982 (2010).

139. Ngernyuang, N., Shao, R., Suwannarurk, K. \& Limpaiboon, T. Chitinase 3 like (CHI3L1) promotes vasculogenic mimicry formation in cervical cancer. Pathology 50, 293-297 (2018).

140. Hanahan, D. \& Weinberg, R. A. Hallmarks of cancer: the next generation. Cell 144, 646-674 (2011)

141. DeNardo, D. G., Andreu, P. \& Coussens, L. M. Interactions between lymphocytes and myeloid cells regulate pro- versus anti-tumor immunity. Cancer Metast. Rev. 29, 309-316 (2010).

142. Grivennikov, S. I., Greten, F. R. \& Karin, M. Immunity, inflammation, and cancer. Cell 140, 883-899 (2010)

143. Qian, B. Z. \& Pollard, J. W. Macrophage diversity enhances tumor progression and metastasis. Cell 141, 39-51 (2010)

144. Wu, W. S. The signaling mechanism of ROS in tumor progression. Cancer Metast. Rev. 25, 695-705 (2006).

145. Chen, C. C., Llado, V., Eurich, K., Tran, H. T. \& Mizoguchi, E. Carbohydrate-binding motif in chitinase 3-like 1 (CHI3L1/YKL-40) specifically activates Akt signaling pathway in colonic epithelial cells. Clin. Immunol. 140, 268-275 (2011).

146. Alfaro, C. et al. Interleukin-8 in cancer pathogenesis, treatment and follow-up Cancer Treat. Rev. 60, 24-31 (2017).

147. Thaker, P. H. et al. Chronic stress promotes tumor growth and angiogenesis in a mouse model of ovarian carcinoma. Nat. Med. 12, 939-944 (2006).

148. Cohen, N. et al. Fibroblasts drive an immunosuppressive and growth-promoting microenvironment in breast cancer via secretion of Chitinase 3-like 1. Oncogene 36, 4457-4468 (2017)

149. Jingjing, Z. et al. MicroRNA-24 modulates Staphylococcus aureus-induced macrophage polarization by suppressing CHI3L1. Inflammation 40, 995-1005 (2017).

150. Chen, Y., Zhang, S., Wang, Q. \& Zhang, X. Tumor-recruited M2 macrophages promote gastric and breast cancer metastasis via M2 macrophage-secreted CHI3L1 protein. J. Hematol. Oncol. 10, 36 (2017).

151. Sakata, K., Shigemasa, K., Nagai, N. \& Ohama, K. Expression of matrix metalloproteinases (MMP-2, MMP-9, MT1-MMP) and their inhibitors (TIMP-1, TIMP-2) in common epithelial tumors of the ovary. Int. J. Oncol. 17, 673-681 (2000).

152. Steenbrugge, J. et al. Anti-inflammatory signaling by mammary tumor cells mediates prometastatic macrophage polarization in an innovative intraductal mouse model for triple-negative breast cancer. J. Exp. Clin. Cancer Res. 37, 191 (2018).

153. Kjaergaard, A. D., Helby, J., Johansen, J. S., Nordestgaard, B. G. \& Bojesen, S. E. Elevated plasma YKL-40 and risk of infectious disease: a prospective study of 94665 individuals from the general population. Clin. Microbiol. Infect. S1198743X, 30035-5 (2020).

154. Kim, M. J. et al. Chitinase 3 -like 1 protein plays a critical role in respiratory syncytial virus-induced airway inflammation. Allergy 74, 685-697 (2019).

155. Kang, M. J. et al. Role of chitinase 3-Like-1 in interleukin-18-induced pulmonary Type 1, Type 2, and Type 17 inflammation; alveolar destruction; and airway fibrosis in the murine lung. Am. J. Respir. Cell Mol. Biol. 53, 863-871 (2015).

156. Long, X. et al. Serum YKL-40 as predictor of outcome in hypersensitivity pneumonitis. Eur. Respir. J. 49, 1501924 (2017).
157. Hozumi, H. et al. Clinical utility of YKL-40 in polymyositis/dermatomyositisassociated interstitial lung disease. J. Rheumatol. 44, 1394-1401 (2017).

158. Jiang, L. et al. Serum YKL-40 level is associated with severity of interstitial lung disease and poor prognosis in dermatomyositis with anti-MDA5 antibody. Clin. Rheumatol. 38, 1655-1663 (2019).

159. Chupp, G. L. et al. A chitinase-like protein in the lung and circulation of patients with severe asthma. N. Engl. J. Med. 357, 2016-2027 (2007).

160. Tang, $\mathrm{H}$. et al. YKL-40 in asthmatic patients, and its correlations with exacerbation, eosinophils and immunoglobulin E. Eur. Respir. J. 35, 757-760 (2010).

161. James, A. J. et al. Increased YKL-40 and chitotriosidase in asthma and chronic obstructive pulmonary disease. Am. J. Respir. Crit. Care Med. 193, 131-142 (2016).

162. Ober, C. et al. Effect of variation in CHI3L1 on serum YKL-40 level, risk of asthma, and lung function. N. Engl. J. Med. 358, 1682-1691 (2008).

163. Zhou, Y. et al. Chitinase 3-like 1 suppresses injury and promotes fibroproliferative responses in Mammalian lung fibrosis. Sci. Transl. Med. 6, 240 ra276 (2014).

164. Leonardi, S. et al. YKL-40 as marker of severe lung disease in cystic fibrosis patients. J. Cyst. Fibros. 15, 583-586 (2016).

165. Vaananen, T. et al. Glycoprotein YKL-40 levels in plasma are associated with fibrotic changes on HRCT in asbestos-exposed subjects. Mediators Inflamm. 2017, 1797512 (2017)

166. Letuve, S. et al. YKL-40 is elevated in patients with chronic obstructive pulmonary disease and activates alveolar macrophages. J. Immunol. 181, 5167-5173 (2008)

167. Lai, T. et al. YKL-40 expression in chronic obstructive pulmonary disease: relation to acute exacerbations and airway remodeling. Respir. Res. 17, 31 (2016).

168. Shan, Z. et al. Chitinase 3-like-1 promotes intrahepatic activation of coagulation through induction of tissue factor in mice. Hepatology 67, 2384-2396 (2018).

169. Wang, Y., Zhong, M., Wang, W. \& Li, Y. H. Chi3l1 regulates APAP-induced liver injury by promoting macrophage infiltration. Eur. Rev. Med. Pharmacol. Sci. 23 4996-5003 (2019).

170. Lee, D. H. et al. Chitinase-3-like-1 deficiency attenuates ethanol-induced liver injury by inhibition of sterol regulatory element binding protein 1-dependent triglyceride synthesis. Metab.: Clin. Exp. 95, 46-56 (2019).

171. Tiriveedhi, V. et al. Protective role of bortezomib in steatotic liver ischemia/ reperfusion injury through abrogation of MMP activation and YKL-40 expression. Transpl. Immunol. 30, 93-98 (2014).

172. Kamal, S. M. et al. Progression of fibrosis in hepatitis C with and without schistosomiasis: correlation with serum markers of fibrosis. Hepatology $\mathbf{4 3}$ 771-779 (2006).

173. Pungpapong, S. et al. Serum fibrosis markers can predict rapid fibrosis progression after liver transplantation for hepatitis C. Liver Transplant. 14, 1294-1302 (2008)

174. Esmat, G. et al. Evaluation of serum biomarkers of fibrosis and injury in Egyptian patients with chronic hepatitis C. J. Hepatol. 46, 620-627 (2007).

175. Fontana, R. J. et al. YKL-40 genetic polymorphisms and the risk of liver disease progression in patients with advanced fibrosis due to chronic hepatitis C. Liver Int. 32, 665-674 (2012).

176. Mehta, P. et al. Diagnostic accuracy of serum hyaluronic acid, FIBROSpect II, and YKL-40 for discriminating fibrosis stages in chronic hepatitis C. Am. J. Gastroenterol. 103, 928-936 (2008).

177. Huang, $H$. et al. CHI3L1 is a liver-enriched, noninvasive biomarker that can be used to stage and diagnose substantial hepatic fibrosis. Omics 19, 339-345 (2015).

178. Yan, L. et al. Serum YKL-40 as a biomarker for liver fibrosis in chronic hepatitis B patients with normal and mildly elevated ALT. Infection 46, 385-393 (2018).

179. Mushtaq, S., Ghani, E., Azam, K. \& Hussain, T. Comparison of chitinase-3-like protein 1, aspartate aminotransferase-to-platelet ratio index, and fibrosis-4 index with shear-wave elastography. Eur. J. Gastroenterol. Hepatol. 31, 357-362 (2019).

180. Wang, L., Liu, T., Zhou, J., You, H. \& Jia, J. Changes in serum chitinase 3-like 1 levels correlate with changes in liver fibrosis measured by two established quantitative methods in chronic hepatitis B patients following antiviral therapy. Hepatol. Res. 48, E283-E290 (2018).

181. Johansen, J. S. et al. Serum YKL-40 is increased in patients with hepatic fibrosis. J. Hepatol. 32, 911-920 (2000).

182. Nojgaard, C. et al. Serum levels of YKL-40 and PIIINP as prognostic markers in patients with alcoholic liver disease. J. Hepatol. 39, 179-186 (2003).

183. Kumagai, E. et al. Serum YKL- 40 as a marker of liver fibrosis in patients with nonalcoholic fatty liver disease. Sci. Rep. 6, 35282 (2016).

184. Aomatsu, T. et al. Faecal chitinase 3-like-1: a novel biomarker of disease activity in paediatric inflammatory bowel disease. Aliment. Pharmacol. Ther. 34, 941-948 (2011). 
185. Buisson, A. et al. Faecal chitinase 3-like 1 is a reliable marker as accurate as faecal calprotectin in detecting endoscopic activity in adult patients with inflammatory bowel diseases. Aliment. Pharmacol. Ther. 43, 1069-1079 (2016).

186. Kawada, M. et al. Chitinase 3-like-1 enhances bacterial adhesion to colonic epithelial cells through the interaction with bacterial chitin-binding protein. Lab. Investig. 88, 883-895 (2008).

187. Low, D. et al. Chitin-binding domains of Escherichia coli ChiA mediate interactions with intestinal epithelial cells in mice with colitis. Gastroenterology 145, 602-612 e609 (2013).

188. Tran, H. T. et al. Chitinase 3-like 1 synergistically activates IL6-mediated STAT3 phosphorylation in intestinal epithelial cells in murine models of infectious colitis. Inflamm. Bowel Dis. 20, 835-846 (2014).

189. Sciborski, K. et al. Plasma YKL-40 levels correlate with the severity of coronary atherosclerosis assessed with the SYNTAX score. Pol. Arch. Intern. Med. 128, 644-648 (2018).

190. Schroder, J. et al. Prognosis and reclassification by YKL-40 in stable coronary artery disease. J. Am. Heart Assoc. 9, e014634 (2020).

191. Michelsen, A. E. et al. Increased YKL-40 expression in patients with carotid atherosclerosis. Atherosclerosis 211, 589-595 (2010).

192. Jung, Y. Y. et al. Atherosclerosis is exacerbated by chitinase-3-like-1 in amyloid precursor protein transgenic mice. Theranostics 8, 749-766 (2018).

193. Gong, Z., Xing, S., Zheng, F. \& Xing, Q. Increased expression of chitinase 3-like 1 in aorta of patients with atherosclerosis and suppression of atherosclerosis in apolipoprotein E-knockout mice by chitinase 3-like 1 gene silencing. Mediat. Inflamm. 2014, 905463 (2014).

194. Aguilera, E. et al. Relationship of YKL-40 and adiponectin and subclinical atherosclerosis in asymptomatic patients with type 1 diabetes mellitus from a European Mediterranean population. Cardiovasc. Diabetol. 14, 121 (2015).

195. Thomsen, S. B., Rathcke, C. N., Zerahn, B. \& Vestergaard, H. Increased levels of the calcification marker matrix Gla protein and the inflammatory markers YKL40 and CRP in patients with type 2 diabetes and ischemic heart disease. Cardiovasc. Diabetol. 9, 86 (2010).

196. Wu, S. et al. Circulating YKL-40 level, but not CHI3L1 gene variants, is associated with atherosclerosis-related quantitative traits and the risk of peripheral artery disease. Int. J. Mol. Sci. 15, 22421-22437 (2014).

197. Batinic, K. et al. YKL-40 is elevated in patients with peripheral arterial disease and diabetes or pre-diabetes. Atherosclerosis 222, 557-563 (2012).

198. Hobaus, C. et al. YKL-40 levels increase with declining ankle-brachial index and are associated with long-term cardiovascular mortality in peripheral arterial disease patients. Atherosclerosis 274, 152-156 (2018).

199. Johansen, J. S. et al. YKL-40 in giant cells and macrophages from patients with giant cell arteritis. Arthritis Rheum. 42, 2624-2630 (1999).

200. Ridker, P. M., Chasman, D. I., Rose, L., Loscalzo, J. \& Elias, J. A. Plasma levels of the proinflammatory chitin-binding glycoprotein YKL-40, variation in the chitinase 3-like 1 gene (CHI3L1), and incident cardiovascular events. J. Am. Heart Assoc. 3, e000897 (2014).

201. Kjaergaard, A. D., Johansen, J. S., Bojesen, S. E. \& Nordestgaard, B. G. Observationally and genetically high YKL-40 and risk of venous thromboembolism in the general population: Cohort and Mendelian Randomization Studies. Arterioscler. Thromb. Vasc. Biol. 36, 1030-1036 (2016).

202. Chen, G. et al. Elevated plasma YKL-40 as a prognostic indicator in patients with idiopathic pulmonary arterial hypertension. Respirology 19, 608-615 (2014).

203. Jafari, B. \& Mohsenin, V. Chitinase-3-like protein-1 (YKL-40) as a marker of endothelial dysfunction in obstructive sleep apnea. Sleep. Med. 25, 87-92 (2016).

204. Marott, S. C. et al. YKL-40 levels and atrial fibrillation in the general population. Int. J. Cardiol. 167, 1354-1359 (2013).

205. Wang, Q. et al. YKL-40 is highly expressed in the epicardial adipose tissue of patients with atrial fibrillation and associated with atrial fibrosis. J. Transl. Med. 16, 229 (2018).

206. El-Asrar, M. A., Elbarbary, N. S., Ismail, E. A. \& Elshenity, A. M. Serum YKL-40 in young patients with beta-thalassemia major: relation to hepatitis $C$ virus infection, liver stiffness by transient elastography and cardiovascular complications. Blood Cells Mol. Dis. 56, 1-8 (2016).

207. Bilim, O. et al. Serum YKL-40 predicts adverse clinical outcomes in patients with chronic heart failure. J. Card. Fail. 16, 873-879 (2010).

208. Hempen, M. et al. YKL-40 is elevated in morbidly obese patients and declines after weight loss. Obes. Surg. 19, 1557-1563 (2009).

209. Rathcke, C. N., Johansen, J. S. \& Vestergaard, H. YKL-40, a biomarker of inflammation, is elevated in patients with type 2 diabetes and is related to insulin resistance. Inflamm. Res. 55, 53-59 (2006).

210. Catalan, V. et al. Increased circulating and visceral adipose tissue expression levels of YKL-40 in obesity-associated type 2 diabetes are related to inflammation: impact of conventional weight loss and gastric bypass. J. Clin. Endocrinol. Metab. 96, 200-209 (2011).
211. Rondbjerg, A. K., Omerovic, E. \& Vestergaard, H. YKL-40 levels are independently associated with albuminuria in type 2 diabetes. Cardiovasc. Diabetol. 10, 54 (2011).

212. Yasuda, T. et al. YKL-40, a new biomarker of endothelial dysfunction, is independently associated with albuminuria in type 2 diabetic patients. Diabetes Res. Clin. Pract. 91, e50-e52 (2011).

213. Nielsen, A. R. et al. Plasma YKL-40: a BMI-independent marker of type 2 diabetes. Diabetes 57, 3078-3082 (2008).

214. Persson, F. et al. High YKL-40 levels predict mortality in patients with type 2 diabetes. Diabetes Res. Clin. Pract. 96, 84-89 (2012).

215. Rathcke, C. N., Persson, F., Tarnow, L., Rossing, P. \& Vestergaard, H. YKL-40, a marker of inflammation and endothelial dysfunction, is elevated in patients with type 1 diabetes and increases with levels of albuminuria. Diabetes Care $\mathbf{3 2}$, 323-328 (2009).

216. Craig-Schapiro, R. et al. YKL-40: a novel prognostic fluid biomarker for preclinical Alzheimer's disease. Biol. Psychiatry 68, 903-912 (2010).

217. Baldacci, F., Lista, S., Cavedo, E., Bonuccelli, U. \& Hampel, H. Diagnostic function of the neuroinflammatory biomarker YKL-40 in Alzheimer's disease and other neurodegenerative diseases. Expert Rev. Proteom. 14, 285-299 (2017).

218. Choi, J., Lee, H. W. \& Suk, K. Plasma level of chitinase 3-like 1 protein increases in patients with early Alzheimer's disease. J. Neurol. 258, 2181-2185 (2011).

219. Alcolea, D. et al. Relationship between beta-secretase, inflammation and core cerebrospinal fluid biomarkers for Alzheimer's disease. J. Alzheimer's Dis. 42, 157-167 (2014).

220. Kester, M. I. et al. Cerebrospinal fluid VILIP-1 and YKL-40, candidate biomarkers to diagnose, predict and monitor Alzheimer's disease in a memory clinic cohort. Alzheimer's Res. Ther. 7, 59 (2015).

221. Olsson, B. et al. The glial marker YKL-40 is decreased in synucleinopathies. Mov. Disord. 28, 1882-1885 (2013).

222. Wildsmith, K. R. et al. Identification of longitudinally dynamic biomarkers in Alzheimer's disease cerebrospinal fluid by targeted proteomics. Mol. Neurodegener. 9, 22 (2014).

223. Mattsson, N. et al. Cerebrospinal fluid microglial markers in Alzheimer's disease: elevated chitotriosidase activity but lack of diagnostic utility. Neuromol. Med. 13, 151-159 (2011).

224. Gispert, J. D. et al. CSF YKL-40 and pTau181 are related to different cerebral morphometric patterns in early AD. Neurobiol. Aging 38, 47-55 (2016).

225. Olsson, B. et al. CSF and blood biomarkers for the diagnosis of Alzheimer's disease: a systematic review and meta-analysis. Lancet Neurol. 15, 673-684 (2016).

226. Hall, S. et al. Longitudinal measurements of cerebrospinal fluid biomarkers in Parkinson's disease. Mov. Disord. 31, 898-905 (2016).

227. Hall, I. E., Stern, E. P., Cantley, L. G., Elias, J. A. \& Parikh, C. R. Urine YKL-40 is associated with progressive acute kidney injury or death in hospitalized patients. BMC Nephrol. 15, 133 (2014).

228. De Loor, J. et al. Urinary chitinase 3-like protein 1 for early diagnosis of acute kidney injury: a prospective cohort study in adult critically ill patients. Crit. Care 20, 38 (2016).

229. Conroy, A. L. et al. Chitinase-3-like 1 is a biomarker of acute kidney injury and mortality in paediatric severe malaria. Malar. J. 17, 82 (2018).

230. De Loor, J. et al. Diagnosis of cardiac surgery-associated acute kidney injury: differential roles of creatinine, chitinase 3-like protein 1 and neutrophil gelatinase-associated lipocalin: a prospective cohort study. Ann. Intensive Care 7, 24 (2017).

231. Malhotra, R. et al. Urine markers of kidney tubule cell injury and kidney function decline in SPRINT Trial participants with CKD. Clin. J. Am. Soc. Nephrol. 15, 349-358 (2020).

232. Montgomery, T. A. et al. Breast regression Protein-39/Chitinase 3-Like 1 promotes renal fibrosis after kidney injury via activation of myofibroblasts. J. Am. Soc. Nephrol. 28, 3218-3226 (2017).

233. Richter, B. et al. YKL-40 and mast cells are associated with detrusor fibrosis in patients diagnosed with bladder pain syndrome/interstitial cystitis according to the 2008 criteria of the European Society for the Study of Interstitial Cystitis. Histopathology 57, 371-383 (2010).

234. Lorenz, G. et al. Mortality prediction in stable hemodialysis patients is refined by YKL-40, a 40-kDa glycoprotein associated with inflammation. Kidney Int. 93, 221-230 (2018).

235. Kocyigit, I. et al. The serum YKL-40 level is associated with vascular injury and predicts proteinuria in nephrotic syndrome patients. J. Atheroscler. Thromb. 22, 257-264 (2015).

236. Sakata, M. et al. YKL-39, a human cartilage-related protein, induces arthritis in mice. Clin. Exp. Rheumatol. 20, 343-350 (2002).

237. Qin, W. et al. Increased expression of the inflammatory protein YKL-40 in precancers of the breast. Int. J. Cancer 121, 1536-1542 (2007). 
238. Shao, R. et al. Breast cancer expression of YKL-40 correlates with tumour grade, poor differentiation, and other cancer markers. Br. J. Cancer 105, 1203-1209 (2011).

239. Dupont, J. et al. Early detection and prognosis of ovarian cancer using serum YKL-40. J. Clin. Oncol. 22, 3330-3339 (2004).

240. Hogdall, E. V. et al. YKL-40 tissue expression and plasma levels in patients with ovarian cancer. BMC Cancer 9, 8 (2009).

241. Vos, K. et al. Raised human cartilage glycoprotein-39 plasma levels in patients with rheumatoid arthritis and other inflammatory conditions. Ann. Rheum. Dis. 59, 544-548 (2000).

242. Matsumoto, T. \& Tsurumoto, T. Serum YKL-40 levels in rheumatoid arthritis: correlations between clinical and laborarory parameters. Clin. Exp. Rheumatol. 19, 655-660 (2001).

243. Johansen, J. S. et al. Serum YKL-40 concentrations in patients with rheumatoid arthritis: relation to disease activity. Rheumatology 38, 618-626 (1999).

244. Johansen, J. S., Kirwan, J. R., Price, P. A. \& Sharif, M. Serum YKL-40 concentrations in patients with early rheumatoid arthritis: relation to joint destruction. Scand. J. Rheumatol. 30, 297-304 (2001).

245. Harvey, S., Whaley, J. \& Eberhardt, K. The relationship between serum levels of YKL-40 and disease progression in patients with early rheumatoid arthritis. Scand. J. Rheumatol. 29, 391-393 (2000).

246. Volck, B. et al. Studies on YKL-40 in knee joints of patients with rheumatoid arthritis and osteoarthritis. Involvement of $\mathrm{YKL}-40$ in the joint pathology. Osteoarthr. Cartil. 9, 203-214 (2001).

247. Verheijden, G. F. et al. Human cartilage glycoprotein-39 as a candidate autoantigen in rheumatoid arthritis. Arthritis Rheum. 40, 1115-1125 (1997).

248. van Bilsen, J. $\mathrm{H}$. et al. Functional regulatory immune responses against human cartilage glycoprotein-39 in health vs. proinflammatory responses in rheumatoid arthritis. Proc. Natl Acad. Sci. USA 101, 17180-17185 (2004).

249. van Lierop, M. J. et al. Endogenous HLA-DR-restricted presentation of the cartilage antigens human cartilage gp-39 and melanoma inhibitory activity in the inflamed rheumatoid joint. Arthritis Rheum. 56, 2150-2159 (2007).

250. Volck, B. et al. YKL-40, a mammalian member of the chitinase family, is a matrix protein of specific granules in human neutrophils. Proc. Assoc. Am. Physicians 110, 351-360 (1998)

251. Sekine, T. et al. Recognition of YKL-39, a human cartilage related protein, as a target antigen in patients with rheumatoid arthritis. Ann. Rheum. Dis. 60, 49-54 (2001).

252. Tsuruha, J. et al. Autoimmunity against YKL-39, a human cartilage derived protein, in patients with osteoarthritis. J. Rheumatol. 29, 1459-1466 (2002)

253. Kzhyshkowska, J., Yin, S., Liu, T., Riabov, V. \& Mitrofanova, I. Role of chitinase-like proteins in cancer. Biol. Chem. 397, 231-247 (2016).

254. Johansen, J. S., Jensen, B. V., Roslind, A. \& Price, P. A. Is YKL-40 a new therapeutic target in cancer? Expert Opin. Ther. Targets 11, 219-234 (2007).

255. Faibish, M., Francescone, R., Bentley, B., Yan, W. \& Shao, R. A YKL-40-neutralizing antibody blocks tumor angiogenesis and progression: a potential therapeutic agent in cancers. Mol. Cancer Ther. 10, 742-751 (2011).

256. Ashizawa, T. et al. Effect of the STAT3 inhibitor STX-0119 on the proliferation of a temozolomide-resistant glioblastoma cell line. Int. J. Oncol. 45, 411-418 (2014).

257. Miyata, $\mathrm{H}$. et al. Combination of a STAT3 Inhibitor and an mTOR inhibitor against a temozolomide-resistant glioblastoma cell line. Cancer Genom. Proteom. 14, 83-91 (2017).

258. Zhang, W. et al. Resveratrol represses YKL-40 expression in human glioma U87 cells. BMC Cancer 10, 593 (2010)

259. Steenbakkers, P. G. et al. Localization of MHC class II/human cartilage glycoprotein-39 complexes in synovia of rheumatoid arthritis patients using complex-specific monoclonal antibodies. J. Immunol. 170, 5719-5727 (2003).

260. Zandbelt, M. M. et al. Intranasal administration of recombinant human cartilage glycoprotein-39. A phase I escalating cohort study in patients with rheumatoid arthritis. J. Rheumatol. 33, 1726-1733 (2006).

261. Sica, A., Schioppa, T., Mantovani, A. \& Allavena, P. Tumour-associated macrophages are a distinct $\mathrm{M} 2$ polarised population promoting tumour progression: potential targets of anti-cancer therapy. Eur. J. Cancer 42, 717-727 (2006).

262. Higashiyama, M. et al. Chitinase 3-like 1 deficiency ameliorates liver fibrosis by promoting hepatic macrophage apoptosis. Hepatol. Res. 49, 1316-1328 (2019).

263. Lee, D. H. et al. Decreased lung tumor development in SwAPP mice through the downregulation of CHI3L1 and STAT 3 activity via the upregulation of miRNA342-3p. Mol. Ther. Nucleic Acids 16, 63-72 (2019).

264. Kim, K. C. et al. Suppression of metastasis through inhibition of chitinase 3-like 1 expression by miR-125a-3p-mediated up-regulation of USF1. Theranostics $\mathbf{8}$, 4409-4428 (2018)

265. Johansen, J. S. Studies on serum YKL-40 as a biomarker in diseases with inflammation, tissue remodelling, fibroses and cancer. Dan. Med. Bull. 53, 172-209 (2006).
266. Xing, Z. et al. IL-6 is an antiinflammatory cytokine required for controlling local or systemic acute inflammatory responses. J. Clin. Investig. 101, 311-320 (1998).

267. Miossec, P. Interleukin-17 in rheumatoid arthritis: if T cells were to contribute to inflammation and destruction through synergy. Arthritis Rheum. 48, 594-601 (2003).

268. Olee, T., Hashimoto, S., Quach, J. \& Lotz, M. IL-18 is produced by articular chondrocytes and induces proinflammatory and catabolic responses. J. Immunol. 162, 1096-1100 (1999).

269. Sohn, M. H. et al. The chitinase-like proteins breast regression protein-39 and YKL-40 regulate hyperoxia-induced acute lung injury. Am. J. Respir. Crit. Care Med. 182, 918-928 (2010).

270. Roslind, A. et al. YKL-40 protein expression is not a prognostic marker in patients with primary breast cancer. Breast Cancer Res. Treat. 112, 275-285 (2008).

271. Johansen, J. S., Cintin, C., Jorgensen, M., Kamby, C. \& Price, P. A. Serum YKL-40: a new potential marker of prognosis and location of metastases of patients with recurrent breast cancer. Eur. J. Cancer 31A, 1437-1442 (1995).

272. Johansen, J. S. et al. High serum YKL-40 levels in patients with primary breast cancer is related to short recurrence free survival. Breast Cancer Res. Treat. 80, 15-21 (2003)

273. Mitsuhashi, A. et al. Serum YKL-40 as a marker for cervical adenocarcinoma. Ann. Oncol. 20, 71-77 (2009).

274. Johansen, J. S. et al. Diurnal, weekly, and long-time variation in serum concentrations of YKL-40 in healthy subjects. Cancer Epidemiol. Biomark. Prev. 17 2603-2608 (2008)

275. Diefenbach, C. S. et al. Preoperative serum YKL-40 is a marker for detection and prognosis of endometrial cancer. Gynecol. Oncol. 104, 435-442 (2007).

276. Kemik, P. et al. Diagnostic and prognostic values of preoperative serum levels of YKL-40, HE-4 and DKK-3 in endometrial cancer. Gynecol. Oncol. 140, 64-69 (2016).

277. Johansen, J. S. et al. Changes of biochemical markers of bone turnover and YKL40 following hormonal treatment for metastatic prostate cancer are related to survival. Clin. Cancer Res. 13, 3244-3249 (2007).

278. Kucur, M. et al. Serum YKL-40 levels and chitotriosidase activity as potential biomarkers in primary prostate cancer and benign prostatic hyperplasia. Urol. Oncol. 26, 47-52 (2008).

279. Pan, J. J. et al. The expression of chitinase 3-like 1: a novel prognostic predictor for hepatocellular carcinoma. J. Cancer Res. Clin. Oncol. 139, 1043-1054 (2013).

280. Zhu, C. B. et al. Elevated serum YKL-40 level predicts poor prognosis in hepatocellular carcinoma after surgery. Ann. Surg. Oncol. 19, 817-825 (2012).

281. Zhu, C. B. et al. Serum YKL-40 independently predicts outcome after transcatheter arterial chemoembolization of hepatocellular carcinoma. PLOS ONE 7, e44648 (2012).

282. Johansen, J. S. et al. Serum YKL-40 in risk assessment for colorectal cancer: a prospective study of 4,496 subjects at risk of colorectal cancer. Cancer Epidemiol. Biomark. Prev. 24, 621-626 (2015).

283. Fijneman, R. J. et al. Proximal fluid proteome profiling of mouse colon tumors reveals biomarkers for early diagnosis of human colorectal cancer. Clin. Cancer Res. 18, 2613-2624 (2012).

284. Tanwar, M. K., Gilbert, M. R. \& Holland, E. C. Gene expression microarray analysis reveals YKL-40 to be a potential serum marker for malignant character in human glioma. Cancer Res. 62, 4364-4368 (2002).

285. Gallego Perez-Larraya, J. et al. Diagnostic and prognostic value of preoperative combined GFAP, IGFBP-2, and YKL-40 plasma levels in patients with glioblastoma. Cancer 120, 3972-3980 (2014).

286. Nutt, C. L. et al. YKL-40 is a differential diagnostic marker for histologic subtypes of high-grade gliomas. Clin. Cancer Res. 11, 2258-2264 (2005).

287. Hormigo, A. et al. YKL-40 and matrix metalloproteinase- 9 as potential serum biomarkers for patients with high-grade gliomas. Clin. Cancer Res. 12 5698-5704 (2006).

288. Thorn, A. P., Daugaard, S., Christensen, L. H., Christensen, I. J. \& Petersen, M. M YKL-40 protein in osteosarcoma tumor tissue. APMIS 124, 453-461 (2016).

289. Mylin, A. K. et al. Serum YKL-40 and bone marrow angiogenesis in multiple myeloma. Int. J. Cancer 124, 1492-1494 (2009).

290. Wang, J., Sheng, Z., Yang, W. \& Cai, Y. Elevated serum concentration of chitinase 3-Like 1 is an independent prognostic biomarker for poor survival in lung cancer patients. Cell. Physiol. Biochem. 38, 461-468 (2016).

291. Egberts, F. et al. Comparative study of YKL-40, S-100B and LDH as monitoring tools for Stage IV melanoma. Eur. J. Cancer 48, 695-702 (2012).

292. Ma, B. et al. Role of chitinase 3 -like-1 and semaphorin $7 a$ in pulmonary melanoma metastasis. Cancer Res. 75, 487-496 (2015).

293. Schmidt, $H$. et al. Serum YKL-40 predicts relapse-free and overall survival in patients with American Joint Committee on Cancer stage I and II melanoma. J. Clin. Oncol. 24, 798-804 (2006). 
20

294. Liu, C., Li, Q., Zhou, X., Kolosov, V. P. \& Perelman, J. M. The chitinase-like protein YKL-40 increases mucin5AC production in human bronchial epithelial cells. Exp. Cell Res. 319, 2866-2873 (2013).

295. Xu, T. et al. YKL-40 level and hypertension incidence: a Population-Based Nested Case-Control Study in China. J. Am. Heart Assoc. 5, e004534 (2016).

296. Dieset, I. et al. An association between YKL-40 and type 2 diabetes in psychotic disorders. Acta Psychiatr. Scand. 139, 37-45 (2019).

297. Volck, B., Ostergaard, K., Johansen, J. S., Garbarsch, C. \& Price, P. A. The distribution of YKL-40 in osteoarthritic and normal human articular cartilage. Scand. J. Rheumatol. 28, 171-179 (1999).

298. Conrozier, T. et al. Serum levels of YKL-40 and C reactive protein in patients with hip osteoarthritis and healthy subjects: a cross sectional study. Ann. Rheum. Dis. 59, 828-831 (2000).

299. Vaananen, T. et al. YKL-40 as a novel factor associated with inflammation and catabolic mechanisms in osteoarthritic joints. Mediators Inflamm. 2014, 215140 (2014).

300. Szychlinska, M. A. et al. Co-expression and co-localization of cartilage glycoproteins CHI3L1 and lubricin in osteoarthritic cartilage: morphological, immunohistochemical and gene expression profiles. Int. J. Mol. Sci. 17, 359 (2016).
301. Baeten, D. et al. Detection of major histocompatibility complex/human cartilage gp-39 complexes in rheumatoid arthritis synovitis as a specific and independent histologic marker. Arthritis Rheum. 50, 444-451 (2004).

\section{(c) (i)}

Open Access This article is licensed under a Creative Commons Attribution 4.0 International License, which permits use, sharing, adaptation, distribution and reproduction in any medium or format, as long as you give appropriate credit to the original author(s) and the source, provide a link to the Creative Commons license, and indicate if changes were made. The images or other third party material in this article are included in the article's Creative Commons license, unless indicated otherwise in a credit line to the material. If material is not included in the article's Creative Commons license and your intended use is not permitted by statutory regulation or exceeds the permitted use, you will need to obtain permission directly from the copyright holder. To view a copy of this license, visit http://creativecommons. org/licenses/by/4.0\%.

(c) The Author(s) 2020 